NBER WORKING PAPER SERIES

\title{
CASH FOR CARBON: \\ A RANDOMIZED CONTROLLED TRIAL OF PAYMENTS FOR ECOSYSTEM SERVICES TO REDUCE DEFORESTATION
}

\author{
Seema Jayachandran \\ Joost de Laat \\ Eric F. Lambin \\ Charlotte Y. Stanton \\ Working Paper 22378 \\ http://www.nber.org/papers/w22378
NATIONAL BUREAU OF ECONOMIC RESEARCH
1050 Massachusetts Avenue
Cambridge, MA 02138
June 2016

We thank Robin Audy, Rebekah Chang, Alejandro Favela, Stephen Kagera, Meg Kearns, Lydia Kim, Pricilla Marimo, Ellen Moscoe, Suanna Oh, Alexander Persaud, Jaye Stapleton, and Nancy Thomas for outstanding research assistance; Chimpanzee Sanctuary Wildlife Conservation Trust, Government of Uganda National Environment Management Authority, Innovations for Poverty Action (including Pia Raffler and Doug Parkerson), International Institute for Environment and Development, Nature Harness Initiatives, and Katoomba Group for collaborating on the project; Rebecca Dizon-Ross, Kelsey Jack, Cynthia Kinnan, Molly Lipscomb, Lee Lockwood, Dave Marvin, Stefano Pagiola, and several seminar participants for helpful comments; and the Global Environment Facility, through the United Nations Environment Programme, and the International Initiative for Impact Evaluation (3ie) for funding. Jayachandran also thanks the National Science Foundation for funding (SES-1156941). The views expressed in this article are not necessarily those of the partner organizations, funders, their members, nor the National Bureau of Economic Research.

NBER working papers are circulated for discussion and comment purposes. They have not been peer-reviewed or been subject to the review by the NBER Board of Directors that accompanies official NBER publications.

(C) 2016 by Seema Jayachandran, Joost de Laat, Eric F. Lambin, and Charlotte Y. Stanton. All rights reserved. Short sections of text, not to exceed two paragraphs, may be quoted without explicit permission provided that full credit, including (C) notice, is given to the source. 
Cash for Carbon: A Randomized Controlled Trial of Payments for Ecosystem Services to Reduce Deforestation

Seema Jayachandran, Joost de Laat, Eric F. Lambin, and Charlotte Y. Stanton

NBER Working Paper No. 22378

June 2016

JEL No. O10,O13,Q23,Q54

\section{ABSTRACT}

This paper evaluates a Payments for Ecosystem Services (PES) program in western Uganda that offered forest-owning households cash payments if they conserved their forest. The program was implemented as a randomized trial in 121 villages, 60 of which received the program for two years. The PES program reduced deforestation and forest degradation: Tree cover, measured using high-resolution satellite imagery, declined by $2 \%$ to $5 \%$ in treatment villages compared to $7 \%$ to $10 \%$ in control villages during the study period. We find no evidence of shifting of treecutting to nearby land. We then use the estimated effect size and the "social cost of carbon" to value the delayed carbon dioxide emissions, and compare this benefit to the program's cost.

Seema Jayachandran

Department of Economics

Northwestern University

2001 Sheridan Road

Evanston, IL 60208

and NBER

seema@northwestern.edu

Joost de Laat

Porticus Foundation

joostdelaat@gmail.com
Eric F. Lambin

Department of Earth System Science

Stanford University

elambin@stanford.edu

Charlotte Y. Stanton

Carnegie Institution for Science

charlottestanton@gmail.com 


\section{Introduction}

Deforestation is responsible for $12 \%$ to $15 \%$ of anthropogenic carbon emissions, making it the second largest source of carbon emissions after fossil fuel combustion (Canadell et al., 2007; Van der Werf et al., 2009). Trees absorb carbon dioxide through photosynthesis, and store the carbon in their biomass. When a tree is cut down, it stops absorbing carbon dioxide, and, as it decomposes or is burned, its store of carbon is released into the atmosphere.

Reducing carbon emissions is, of course, crucial for mitigating climate change. Curbing deforestation is believed to be one of the most cost-effective ways to do so (Stern, 2006; Nabuurs et al., 2007). The reason is simple: Most deforestation today occurs in developing countries, and the opportunity cost of averted deforestation in such settings - for example, forgone subsistence farming on the cleared land - is often much lower than the cost of behavioral or technological changes to reduce carbon emissions in high-income countries.

Addressing deforestation in developing countries is, thus, a key pillar of international climate policy. REDD+ (Reducing Emissions from Deforestation and Forest Degradation) is a United Nations mechanism through which developing countries are rewarded financially for preservation of forestland; annually, about $\$ 500$ million dollars flow to developing countries (Silva-Chávez, Schaap, and Breitfeller, 2015).1 The Paris Agreement negotiated in 2015 bolstered the role of REDD+ in climate policy (United Nations FCCC, 2015) $2^{2}$

To put REDD+ into action, one needs to identify effective on-the-ground interventions that reduce deforestation. This paper provides the first rigorous evaluation of a promising and popular type of intervention, namely financial incentives for forest-owning individuals or communities to keep their forest intact. This type of policy is called Payments for Ecosystem Services (PES); payments are made conditional on voluntary pro-environment

\footnotetext{
${ }^{1} \mathrm{~A}$ commonly used definition of forest is an area at least 0.5 to 1 hectares in size with tree crown cover exceeding $10 \%$ to $30 \%$ of the area (United Nations FCCC, 2002). Deforestation is a reduction in the amount of land that meets the definition of forest, while forest degradation is selective tree-clearing that does not reduce the amount of land that meets the definition of forest. In this paper, we use the term deforestation to encompass deforestation and forest degradation.

${ }^{2}$ Article 5 states that "Parties are encouraged to take action to implement and support, including through results-based payments... policy approaches and positive incentives for activities relating to reducing emissions from deforestation and forest degradation...in developing countries."
} 
behaviors (Ferraro and Kiss, 2002; Wunder, 2007; Engel, Pagiola, and Wunder, 2008). PES is the environmental version of a well-known policy instrument in developing countries, conditional cash transfers (CCTs), which are more commonly used to promote child health and education.

Despite the widespread use and growing popularity of PES, its effectiveness and costeffectiveness are open questions. Individuals might be unresponsive to the incentives, leading to small impacts. In addition, even if some people respond to the incentives, cost-effectiveness could be low if, absent the payments, many participants would have engaged in the incentivized behavior anyway. In the case of PES, this problem of inframarginality is often called "additionality": How much additional forest cover does a PES program actually cause? Another concern is that individuals will simply shift their tree-cutting from land covered by the PES contract to other nearby land.

This paper is a randomized evaluation of a PES intervention that was piloted precisely to measure the causal impacts on forest cover. The PES program offered private owners of forestland in western Uganda payments if they refrained from clearing trees. The program was designed and implemented by a local non-governmental organization (NGO). The study was carried out in 121 villages with private forest owners (PFOs); 60 of the villages were randomly selected to be in the treatment group. In treatment villages, the PES program was marketed to PFOs and they were eligible to enroll. Over the two-year pilot program from 2011 to 2013, for each hectare of forest they owned, enrollees received 70,000 Ugandan shillings (UGX), or $\$ 28$ in 2012 US dollars, per year if they complied with the contract $:^{3}$ The implementing NGO employed forest monitors who conducted spot checks of enrollees' land to check for recent tree-clearing. The program also offered additional payments in exchange for planting tree seedlings.

We measure the impact of the program on forest cover by analyzing satellite imagery. Specifically, we tasked a very high resolution commercial satellite, QuickBird, to take images of the study region at baseline and endline and classified each pixel as tree-covered or not

\footnotetext{
${ }^{3}$ The average exchange rate during the study period was approximately 2500 UGX $=1$ US dollar.
} 
using object-based image analysis, a remote-sensing technique for cases where pixels are smaller than the objects of interest. The QuickBird pixel size is 2.4 by 2.4 meters, smaller than the crown of a typical mature tree. By comparing PFOs' land in treatment and control villages, we can assess how many additional hectares of tree cover the program generated.

We find that the PES program significantly reduced deforestation ${ }^{4}$ Tree cover declined by about $7 \%$ to $10 \%$ between baseline and endline on PFOs' land in control villages, but only by $2 \%$ to $5 \%$ in treatment villages. The effect size corresponds to 0.27 additional hectares of tree cover per eligible program participant. These results are robust across different specifications. We also estimate village-wide effects, and find that PFOs did not simply shift their tree-clearing to other land in the village. We also show that there is no evidence of leakage of deforestation to government forest reserves and no evidence of the program affecting deforestation in control villages.

The above estimates are intent-to-treat effects, i.e., treatment effects per eligible PFO. Program take-up was 32\%; the compliance among enrollees, as assessed by the implementing NGO, was $80 \%$. Surprisingly, the intent-to-treat proportional reduction in deforestation is larger than the take-up rate, suggesting that enrollees had higher-than-average counterfactual deforestation. Thus, we do not find evidence that PFOs who were anyway planning to keep their forest intact enrolled in the PES program at an especially high rate.

What is also surprising is that the take-up rate was only $32 \%$ given there was no penalty for signing up and not complying. Most of the low take-up seems to be explained by insufficient marketing of the program. In our endline survey, many PFOs reported that they were unaware of the program or did not know how to sign up. In addition, some PFOs were wary of signing the PES contract, fearful that it was a ploy to steal their land. Only a small minority said they were uninterested in complying so did not take up, which is consistent with relatively little selection into the program based on low counterfactual deforestation.

After presenting the program impacts on tree cover, we provide a rough assessment of cost-effectiveness in terms of averted carbon dioxide $\left(\mathrm{CO}_{2}\right)$ emissions. We estimate that

\footnotetext{
${ }^{4}$ Seedlings planted as part of the program still had small tree crowns at endline, so avoided deforestation rather than reforestation accounts for the vast majority of the gain in forest cover that we estimate.
} 
for each $\$ 0.25$ in payments, or $\$ 0.57$ in total program costs, a ton of $\mathrm{CO}_{2}$ emissions due to deforestation was delayed. We then calculate the externality benefit of the delayed emissions, using a "social cost of carbon" (SCC) of $\$ 39$ (in 2012 US dollars) per ton (Interagency Working Group on Social Cost of Carbon, 2013). The SCC is the benefit of permanently averting $\mathrm{CO}_{2}$ emissions, while this 2-year program's benefit was to delay deforestation and emissions. To quantify the delay, we need to make assumptions about deforestation after the program ends, which we do not observe in our data. Our base case scenario assumes PFOs deforest at a $50 \%$ higher rate than usual after the program ends, converging to the control group after four years. The social benefit of the delayed $\mathrm{CO}_{2}$ emissions is then $\$ 1.11$ per ton, or roughly 2 times the $\$ 0.57$ program cost. $5^{5}$

We repeat the calculation for a range of assumptions. At one extreme, if PFOs catch up on their backlog of avoided deforestation the moment the program ends, the benefitcost ratio falls to 0.7. At the other extreme, if PFOs pause their deforestation during the intervention and then resume deforesting at their typical rate, not an accelerated rate, after the program ends, then the benefit cost-ratio rises to 12.3. This last scenario, which represents a permanent delay in deforestation, is the most relevant one for extrapolating to a permanent or longer-duration program.

Note that the calculations above quantify the gross reduction in $\mathrm{CO}_{2}$ from delayed deforestation in our sample, but the net reduction in global $\mathrm{CO}_{2}$ emissions from the program depends on behavioral responses that are beyond the scope of what our study can measure (e.g., How much less charcoal did urban consumers use? Which fuel types did they shift to?). Moreover, the general equilibrium effects of such a program depend on how widely it is scaled up. Nonetheless, our finding that PES appears to be an effective way to reduce $\mathrm{CO}_{2}$ emissions stands in sharp contrast to assessments of most approaches; few other policies

\footnotetext{
${ }^{5}$ We assume a uniform rate of deforestation absent the program. Carbon from cleared trees is not emitted instantaneously; we assume the average time from tree-clearing until $\mathrm{CO}_{2}$ emissions is 10 years. The SCC is projected to rise over time at 1.9\% per year (Greenstone, Kopits, and Wolverton, 2011; Interagency Working Group on Social Cost of Carbon, 2013). It rises because of growth in income per capita and population, and because the marginal damage from a ton of emissions is higher when climate change has progressed further, e.g., when global temperatures are higher (Nordhaus, 2014). We use a 3\% discount rate.

${ }^{6}$ See Section 6 for discussion of the additional assumptions needed to value a permanent delay in deforestation, as well to extrapolate to a permanent program.
} 
come close to breaking even. For example, policies in the United States such as hybrid and electric vehicle subsidies or ethanol subsidies have costs per ton of averted $\mathrm{CO}_{2}$ that far exceed the SCC (Knittel, 2012; Gayer and Parker, 2013).

We complement the remote sensing analysis by measuring program impacts via a household survey. There are several noteworthy findings from the survey data. First, consistent with the remote sensing results, self-reported tree-clearing was much lower in treatment villages. Second, treated PFOs took steps to protect their land from encroachers, decreasing others' access to it and patrolling it more vigilantly. Third, the program did not seem to have appreciable effects on participants' consumption or other measures of current economic well-being, which is not too surprising. The large impacts on forest cover imply that PFOs did reduce deforestation and hence forwent income; the PES payments offset this income loss but did not, on net, enrich them. At the same time, because participation was voluntary, the program is unlikely to have impoverished them, although a participant might choose lower temporary income in exchange for building up assets, i.e., owning more intact forest. Note that unlike many CCTs, this program, by focusing on landowners, did not target the very poorest in these communities, and the payment amount in fact scaled up with the size of the landholding. Thus, the program may have widened within-village wealth inequality. The net welfare benefits of the program depend on not just the $\mathrm{CO}_{2}$ impacts, but also these possible unintended negative effects as well as other positive impacts such as increased biodiversity and income redistribution from international donors to a developing country.

Climate change is one of, if not the most, significant environmental challenge we face, yet we lack evidence on what policies can mitigate it cost-effectively. The main contribution of this paper is to provide evidence on this important question. We assess a widely-used approach to reduce carbon emissions, providing some of the most rigorous evidence to date evaluating any type of policy aimed at reducing carbon emissions. Scholars have noted the need for high-quality evaluations of environmental policies in general and, given its growing popularity among policy makers, PES in particular (Greenstone and Gayer, 2009, Ferraro and Patanayak, 2006; Ferraro et al., 2015). 
The most widely studied PES project is Costa Rica's Pago por Servicios Ambientaless (PSA). Pattanayak, Wunder, and Ferraro (2010) review the literature on PSA and conclude that "studies give widely divergent results," and many have serious methodological limitations. Many case studies report large, positive impacts on forest cover, but likely suffer from omitted variable bias. The most convincing studies use covariate or propensity-score matching methods, but even here, the estimated impacts on forest cover range from very small to moderately large (Arriagada et al., 2012; Robalino and Pfaff, 2013). PES programs in China, Mozambique, and Mexico, among other settings, have also been studied (Uchida et al., 2007; Hegde and Bull, 2011; Alix-Garcia, Shapiro, and Sims, 2012).

The paper is also related to recent randomized evaluations of tree-planting programs (Jack, 2013; Jack et al., 2015) and other studies on forest conservation in developing countries (Foster and Rosenzweig, 2003; Edmonds, 2002; Somanathan, Prabhakar, and Mehta, 2009; Burgess et al., 2012; Alix-Garcia et al., 2013; Assunção et al., 2014). More broadly, we contribute to the literature in economics on environmental issues in developing countries (Greenstone and Jack, 2015). Finally, this paper has links to the literature evaluating CCTs, differing from most previous studies through its focus on environmental protection Fiszbein, Schady, and Ferreira, 2009).

The rest of the paper is organized as follows. Section 2 describes the study sample, randomization, and PES program. Section 3 then describes the data sources, and section 4 provides descriptive statistics on the sample and lays out the empirical strategy. Section 5 presents the results on the impacts of the PES program on deforestation and other outcomes, and section 6 translates the impacts into averted carbon emissions and assesses program costeffectiveness based on the social cost of carbon. Section 7 presents concluding remarks.

\section{Study design and description of PES program}

\subsection{Study setting}

The study was conducted in 121 villages in two districts in western Uganda, Hoima and Kibaale. Forests cover an eighth of Uganda's land area, concentrated in the western region. 
Uganda's deforestation rate between 2005 and 2010 was $2.7 \%$ a year, the third highest in the world $(\mathrm{FAO}, 2010)$. The pace of deforestation is even faster on privately-owned land, which represents about $70 \%$ of the forest in Uganda (NEMA, 2008). As in much of Africa, the main drivers of deforestation in the study region are subsistence agriculture and domestic demand for timber and charcoal (Fisher, 2010).

In addition to reducing atmospheric $\mathrm{CO}_{2}$, forests also increase biodiversity. Many species are threatened by deforestation in western Uganda, notably chimpanzees, an endangered species that is important for Uganda's tourism industry. Other benefits of forest conservation include watershed protection and reduced siltation and flooding (Nabuurs et al., 2007).

\subsection{Sample of villages and forest owners}

To determine the study sample, we first conducted a census of all private forest owners (PFOs) in all villages with forest in Hoima (late 2010) and northern Kibaale (early 2011). Villages with forest were identified using Landsat satellite imagery overlain with administrative boundaries. Our field team visited these villages, met with the LC1 chairperson (elected village head), explained the study, and asked him to assemble 3 to 4 knowledgeable PFOs. This group then drew a rough map of the village and listed all the people who owned forest in the village. While most PFOs do not have a formal land title, which family de facto owns each plot of land is generally agreed upon within the village; the most common form of land dispute is among family members. The field team then followed up with at least 3 spot checks per village. Through this process, we identified 189 villages in Hoima and 91 villages in Kibaale with at least 1 PFO.

We narrowed this set of 280 villages to our sample of 121 villages by first excluding villages with fewer than 6 or more than 25 PFOs.7 We then excluded parishes (the administrative unit above a village) with only 1 eligible village because we had not yet determined whether a lottery to choose treatment villages would be conducted in each parish or each

\footnotetext{
${ }^{7}$ We excluded villages with more than 25 PFOs because the project had a fixed budget for payments, and, with the village as the unit of randomization, additional PFOs per village add only limited statistical power. We excluded villages with fewer than 6 PFOs due to the fixed cost of working in a village and desire to have statistical power to measure village-level effects.
} 
subcounty (administrative unit above a parish). We excluded two parishes in Kibaale district with very little intact forest; these were the only parishes with forest in their subcounties, so excluding them reduced the geographic spread of the study. Finally, one subcounty (19 villages) was set aside for a pilot.8

We then conducted a baseline survey of PFOs in the sample villages in April to May 2011. In these villages, 1449 PFOs had been listed in the census, and we completed baseline surveys of $1174(81 \%)$ of them. The main reasons for non-response were that we could not locate the PFO, or he stated that he was not a PFO. Some PFOs also refused to participate. An additional criterion to be in our final sample is that we collected valid GPS coordinates for the PFO's home at baseline. GPS coordinates allow us to identify the PFO's home in the satellite imagery and, thus, are necessary for having valid remote sensing data. The main reasons for missing GPS data were malfunctioning of the GPS units or enumerator error. The sample for our analysis comprises the 1099 PFOs who completed the baseline survey and for whom we have GPS coordinates.

\subsection{Randomization}

After the baseline survey, 60 of the villages were randomly selected to be in the treatment group. The randomization was conducted via public lotteries held in each of the 7 subcounties in our sample. In advance of each lottery, we divided the sample villages in the subcounty into two sets, balanced on covariates..$^{9}$ The LC3 chairperson (elected head of the subcounty) or a stand-in drew one of the two lists out of a bin. This selected list constituted the treated

\footnotetext{
${ }^{8}$ Kyabigambire was chosen as the pilot subcounty because the implementing NGO had close ties to the community and conducted its other activities there. At the NGO's request, four villages where they had very close ties were guaranteed the program. In the other 15 villages, we conducted a pilot of the baseline survey, subcounty lottery, program implementation, and endline survey; five villages were chosen for the treatment group. The lottery and program launch occurred in June 2011, two months before the main program launch.

${ }^{9}$ We first generated permutations that divided the villages into two sets differing in size by no more than one village. In subcounties with few sample villages, we constructed all possible permutations and for subcounties with many villages, for computational reasons, we generated a random sample of 1000 permutations. We then tested for balance on four village-level variables: number of PFOs in the sample, distance to a road, average per capita income, and average size of landholding. We considered the two sets of villages balanced if the standardized difference in the mean of each variable was less than 0.25 . For each subcounty, among the balanced permutations, we randomly chose one to use in the public lottery. This procedure of prespecifying the set of balanced randomizations has advantages over re-randomizing until a threshold level of balance is achieved or choosing the most balanced permutation (Imbens, 2011).
} 
villages. The lotteries occurred between August and December 2011. Of the 1099 PFOs in the sample, 564 reside in treatment villages, and the remaining 535 are in control villages.

\subsection{PES program}

The PES program was funded via a grant from the Global Environment Facility, through the United Nations Environment Programme, to the Ugandan government's National Environment Management Authority (NEMA). NEMA subcontracted the design, implementation, and management of the two-year program to a Ugandan conservation non-profit, Chimpanzee Sanctuary and Wildlife Conservation Trust (CSWCT). CSWCT's main activity is operating a chimpanzee refuge near Entebbe, but a secondary activity is promoting conservation of the chimpanzees' natural habitat in western Uganda. Prior to running this PES program, their work in western Uganda with PFOs included community education about conservation and promoting alternative livelihoods to agriculture such as beekeeping.

After the lotteries occurred, we gave CSWCT the list of treatment villages, and they implemented the program. They rolled out the program, subcounty by subcounty, beginning in August 2011 and reaching the last subcounty in January 2012. Their first step when entering a community was to hold a parish-level meeting for eligible PFOs to advertise and explain the program. They then worked with interested PFOs to verify their forest land, measure its area, and determine their eligibility. They explained and helped PFOs fill out and sign the PES contract form. For those who signed up, CSWCT monitored their land via spot checks and made annual payments to those who complied with the contract 10 The monitoring occurred through in-person spot checks once every one or two months, during which the CSWCT employee checked for fresh tree stumps or other signs of cleared forest.

The terms of the PES contract were set by CSWCT, with input from other project partners and using PES programs in other countries as a guide. The contract stipulated that the PFO would conserve his entire existing forest and could not cut down any mediumsized trees (trees with a trunk diameter at breast height $(\mathrm{DBH})$ of 10 to 50 centimeters $(\mathrm{cm})$ ).

\footnotetext{
${ }^{10}$ Some PFOs who signed up for the program are not in our sample, either because we did not identify them as PFOs in our census or they did not complete our baseline survey.
} 
He was allowed to cut selected mature trees $(>50 \mathrm{~cm} \mathrm{DBH})$, determined by the number of mature trees per species in a given forest patch. This provision was to give PFOs a small amount of leeway in case of emergencies. Participants were allowed to cut small trees $(<10$ cm DBH) for home use and to gather firewood from fallen trees.

An important consideration in designing the contract was that it be simple enough to explain to PFOs and to assess compliance. Hence, the contract is much blunter than what would be prescribed for "optimal" forest management. Its goal was to incentivize improved forest management relative to the status quo. This tradeoff between nuanced, multi-faceted requirements and the feasibility of monitoring compliance is inherent to all PES programs, and essentially all incentive contracts.

Enrollees who complied, as determined by CSWCT's monitoring, received a cash payment of 70,000 UGX (\$28) per hectare of forest per year. The average amount of forest area owned is 2 hectares, yielding a payment of $\$ 56$ a year for compliance, which is equal to $5 \%$ $(16 \%)$ of average (median) annual household income, as reported in the baseline survey. ${ }^{11}$ To gauge how this payment level compares to the opportunity cost of keeping forest intact, a large tree that can be used to make lumber sells for $\$ 20$ to $\$ 40$. At baseline, $29 \%$ of PFOs reported earning revenue from timber products in the past one year, and among these, the mean (median) revenue was $\$ 151(\$ 40)$. The second type of forgone income is from cultivation that would have occurred on cleared land. While most households consume all of the crops that they grow, among households that sell crops for cash, self-reported income is in the range of $\$ 30$ to $\$ 100$ per hectare of cultivated land; if a PFO clears new land, he usually clears one or two 40 square meter (0.16 hectare) plots.

\footnotetext{
${ }^{11}$ Costa Rica's PAS program, launched in 1997, and Mexico's Pagos de Servicios Ambientales Hidrológicos (PSAH) program, launched in 2003, are two of the major deforestation PES programs worldwide, and a comparison to them is useful (Wunder, Engel, and Pagiola, 2008). Both make annual cash payments like the CSWCT program. The payment level (in nominal USD) is $\$ 65$ per hectare (ha) per year for PAS (1.2\% of Costa Rica's 2006 GDP per capita) and $\$ 27$ to $\$ 36$ per ha per year (0.4\% to 0.6\% of Mexico's 2003 GDP per capita) for PSAH. The $\$ 28$ per ha per year payment in the CSWCT program is $4.7 \%$ of Uganda's 2011 GDP per capita. PSA requires a minimum forest area to enroll of 2 ha, and PSAH requires 50 ha; the CSWCT program did not have a minimum size. PAS and PSAH offer five-year contracts; the CSWCT contract length was two years. Monitoring for PSA and PSAH is done via annual remote sensing and periodic onthe-ground spot checks, while CSWCT used frequent on-the-ground monitoring. Among other differences, PSAH deemed forest with tree density less than $80 \%$ ineligible, and PSA required fencing the enrolled forest.
} 
PES enrollees also had the option to dedicate up to 2 hectares of cleared forest to reforestation. CSWCT provided the seedlings, and the PFO received 70,000 UGX per hectare per year if the seedlings survived. About half of enrollees took up this option. We focus on the averted deforestation component of the program because it was more significant in terms of payments, take-up, and contributions to tree cover. However, when comparing the amount of money paid to the amount of avoided deforestation, we include the payments for reforestation, as this extra option and payment might have induced some PFOs to enroll. (PFOs were not allowed to take up just the reforestation component; all enrollees were required to avoid deforestation on their forest land.)

\section{Data}

\subsection{Satellite data}

Our main outcome is forest cover on the sample households' land. We analyze satellite images of the study region taken at baseline and endline to identify forest cover, or more precisely, tree cover. We do not use the restricted definition of forest based on a minimum contiguous area covered by trees, as we are interested in the total effect on tree cover, inclusive

of selective cutting of trees within the forest (degradation) and any shifting of tree-clearing from "official" forest to other land.

\subsubsection{QuickBird satellite images}

The data source for measuring tree cover is QuickBird satellite imagery. QuickBird is a commercial satellite that captures images with a multispectral resolution of 2.4 by 2.4 meters. We tasked the QuickBird satellite to take images of our 2461 square kilometer study region at baseline and endline (at a cost of $\$ 23$ per square kilometer per wave).

QuickBird cannot image an area as large as our study region on one flyover. Thus our baseline and endline image each consist of five to six vertical strips taken during north-tosouth flyovers on different days. It required multiple passes over some strips to obtain an image that, in aggregate for the study region, had less than $15 \%$ cloud cover, which is the quality standard that the vendor guarantees. 
Most of the baseline images were collected in May to June 2011. Due to an extended rainy season, the last strips of the image were collected in December 2011 and January 2012, which is a few months after the program was rolled out. This timing would likely attenuate our estimated program effects; relative to control villages, treated villages should (and do) look more forested at baseline if the program has been in place and has been having impacts for a few months, which attenuates the treatment effect size that is estimated. In the analysis, we show that the results are robust to restricting the sample to observations where the lottery occurred after the baseline image was taken (and indeed these results are larger).

We obtained our endline images while the program was still in effect. At scale-up, this type of PES program would likely be in place indefinitely or at least for a long duration, but this trial PES program lasted for two years. Once the financial payments end, PFOs have no incentive not to deforest their land, and thus a zero impact after the program is over does not mean that the program did not delay carbon emissions. The estimate of interest for a temporary program is to measure the postponement of deforestation it caused.

To avoid delays in the endline images such as occurred at baseline, we tasked the satellite to begin taking images in December 2012. The first strip was taken in December 2012, and most of the area was imaged between January and March 2013. The program was in place through at least August 2013 in all treatment villages. We estimate effects when the program had been in place for on average 1.5 years.

\subsubsection{Remote sensing analysis}

The remote sensing analysis was carried out by the Stanford Spatial Analysis Center. The initial step was to pre-process the images, for example to combine the image strips that comprise the overall baseline or endline image of the study region and to adjust for solar zenith angle and Earth-Sun distance at acquisition time. This step and subsequent ones were applied to the image area within the study village administrative boundaries, which were obtained from the Ugandan Bureau of Statistics.

Then the images were analyzed to classify each pixel as having tree cover or not. This 
was done via object-based image analysis (OBIA), using the eCognition software program (Benz et al., 2004). In OBIA, the image is first segmented into polygons, or objects, with spectral and spatial homogeneity. The researcher chooses several parameters for the segmentation algorithm. A key parameter is scale, or how homogeneous each polygon should be; the parameter is called scale because requiring polygons to be more homogeneous will result in smaller-sized polygons, all else equal. Other parameters govern how much to emphasize homogeneity in color versus shape (e.g., compact shapes, smooth borders). The researcher sets the parameters, looks at the results generated by the segmentation algorithm, and then readjusts the parameters until there is a good match with validation data collected in the field (described in the next subsection). The goal is for the polygons to correspond to real-life objects or features of the landscape such as a tree crown or a segment of a dirt road.

OBIA is used for analysis of very high resolution images, i.e., $<5$ meter resolution. More precisely, OBIA is designed for when the objects of interest are larger than the pixel size. At very high resolution, pixel-by-pixel analysis can lead to classification errors due to the high degree of spectral variation within a class (each pixel comprising a tree crown will have a different spectral response); OBIA reduces this misclassification. More importantly, OBIA takes advantage of the rich information contained in the relationship between adjacent pixels (Blaschke, 2010). For example, the shape, size, and context of a cluster of pixels help us identify it as a tree.

After segmentation, the polygon or object is the unit of analysis for classification. In our case, the goal is to classify each object as tree, non-tree, or cloud cover. (Pixels for which the landscape is obscured by clouds become missing data in our analysis.) The classification step uses a knowledge-based expert system in which the researcher defines a mutually exclusive and collectively exhaustive set of classes and a rule set for assigning objects to classes. The rules use several attributes of the objects such as color, shape, and size. In practice, classification is not done after the segmentation is finalized; the entire process is iterative, and the researcher visually inspects the classification results to refine the rules and parameters. ${ }^{12}$

\footnotetext{
${ }^{12}$ Specifically, we used a change detection algorithm in which we first segmented and classified the baseline image, and then segmented the combined multidate images, using the initial classification as an object
} 
We validated the classification rules and improved them by using ground-based data collected from field plots. To define the rules, we applied a classification and regression tree (CART) algorithm which determined the best rules for using the object attributes to predict forest classification, and "trained" the CART system with some of the ground-based data and validated it using the rest of the ground-based data.

\subsubsection{Ground-based forest measurements}

After an initial rough classification of the study area using baseline Landsat satellite images, we sampled 440 geographic locations in the study area and conducted ground-based forestry measurements in spring and summer 2012. The ground measurements were conducted by a Ugandan forestry NGO, Nature Harness Initiatives (NAHI). NAHI followed the standard protocol for conducting a forestry inventory of a 20 meter by 25 meter plot. They identified all trees with a diameter at breast height (DBH) of 10 centimeters or more, recorded the $\mathrm{DBH}$, and estimated crown height and crown diameter. They also counted the number of trees of each species.

\subsubsection{Landsat data}

To improve statistical precision and adjust for any pre-trends in deforestation, we also use Landsat satellite images from the pre-intervention period, specifically from 1990 and 2010. Landsat is a US-government run satellite system with an image resolution of 30 meters. Given this coarser resolution, we use a pixel-by-pixel technique and calculate the probabilistic fraction of each pixel that is photosynthetic vegetation. The classification does not make a distinction between trees and other photosynthetic vegetation such as grass. However, the technique we employ, the Carnegie Landsat Analysis System, was designed to detect deforestation and forest degradation using Landsat images (Asner et al., 2009).

\subsubsection{Unit of observation and missing data}

The main unit of observation in our regression analysis is the PFO. The remote sensing analysis produces a classification of each pixel in the study area, and to convert this to PFO-

attribute in the multidate processing (Desclée, Bogaert, and Defourny, 2006). We classified objects as persistent tree cover, persistent non-tree, tree gain, tree loss, or cloud-covered. Pixels with cloud cover at either baseline or endline are treated as missing data. 
level data, we overlay polygons that represent each PFO's land. While we do not have the actual boundaries of their land, we have the geolocation of their home and their self-reported landholding. As a proxy for their land, we use a circle, centered on their home, that is twice as large as the area of land they own. Note that homes are spread apart in the typical village, as opposed to clustered together; an individual's land is typically contiguous to their home.

We use a circle larger than the actual land owned so that we are likely to include all or most of the land they own and nearby land to which they might shift their tree-cutting. If the land circles excluded much of their land, an estimated reduction in deforestation could simply reflect shifting of tree-cutting from near their home to the periphery. On average, PFOs own 10.8 hectares of land, so the average size of the circles we analyze is 21.6 hectares. We also show the results using circles that are 1 and 3 times the size of the landholding, and because PFOs' estimates of the area of their land might be inaccurate, we also use circles that are equal-sized for each PFO, based on the median land size of 5.3 hectares. Note that 1 PFO has missing data for the amount of land owned and 5 PFOs reported owning no land; for these observations, we have data for a circle around their home using the sample-median land size but not self-reported size ${ }^{13}$

Each circle contains many pixels, and we use the number of pixels classified as treecovered to calculate the total area of tree cover for the PFO. There are two sources of missing data when we calculate this aggregate measure for each PFO. The first is that some of the landscape is obscured by cloud cover at either baseline or endline. (In the change-detection remote-sensing algorithm we use, pixels with cloud cover at either baseline or endline are treated as missing, so the rate of missing data is identical at baseline and endline.) For most of the sample, cloud-free data are available for a subset of the PFO's land area. For 98 PFOs, or $9 \%$ of the sample, the entire land circle is covered by clouds when using land circles that are twice the self-reported land area. These are missing observations. Appendix Table A1 breaks down the sample by availability of different outcome data.

Missing data is uncorrelated with treatment status; the location of cloud cover is essen-

\footnotetext{
${ }^{13}$ These PFOs reported owning forest in the screening questions at the start of the survey, and 3 of them reported owning land at endline.
} 
tially random for our purposes. Note that, mechanically, smaller PFO circles are more likely to have completely missing data. Appendix Table A2 shows that attrition due to missing satellite data is uncorrelated with treatment status or program take-up, but is correlated with land size (column 4). Conditional on land size, the observations with missing satellite data are similar to the main sample (column 5).

A second more minor reason for missing data is that for some PFOs, part of their land circle falls outside the village boundaries and therefore we do not have forest classification for that segment. This leads to $4 \%$ missing data on average and no cases where the entire observation is missing.

To recap, for the majority of our PFOs, some but not all of their land circle has valid data, i.e., cloud-free and within the village boundaries. Conditional on having some data, the average proportion of the land with valid data is $79 \%$. Our outcome measure is, therefore, an aggregate measure based on a sample rather than the universe of pixels representing the land. For statistical efficiency, in the estimation of program impacts, we weight observations by this sampling rate, i.e., the proportion of the PFO's land for which we have remote-sensing data; in practice, the unweighted estimates are similar.

We also conduct analyses at the village level in which the polygon is the administrative boundary of the village. We have less statistical power to estimate program effects when we analyze the entire village because only a portion of land in a village is owned by PFOs. However, the village-level analysis is useful for investigating within-village spillovers. For the village-level data, there are no cases of entirely missing data.

\subsection{Survey data}

Our baseline survey took approximately 1 to 1.5 hours for a respondent to complete and asked about characteristics of the forest owner's land, his past tree-cutting behavior, attitudes toward the environment, consumption, and other topics. We also recorded the location of the PFO's home using hand-held GPS devices.

We conducted a similar survey at endline and use these data to measure program impacts on outcomes other than objective forest cover such as self-reported tree cutting, whether the 
PFO restricted others' access to their land, and socioeconomic outcomes such as expenditures and child health. We also asked questions about the program such as why treatment PFOs did or did not take up the program.

At endline, we successfully re-surveyed 1020 (93\%) of the 1099 baseline PFOs. The survey completion rate was higher in control (95\%) than treatment villages (91\%), and in particular, PFOs in treatment villages who did not take up the program were less likely to participate, as shown in Appendix Table A2, Some of them had moved or died, but most just did not want to participate in the survey; anecdotally, PFOs who were wary of outsiders were less likely to participate in both the program and the endline survey. Thus, for the survey-based results, we calculate Lee bounds on the treatment effects $($ Lee, 2009).

\subsection{Administrative data on program enrollment and payments}

Our final data source is the administrative records of the implementing partner, CSWCT. For each of our baseline PFOs, we know whether he enrolled in the program, how much forest area he enrolled, and how much he was paid each of the two years of the program. We also have data on how much land PFOs set aside for reforestation, how many trees they planted, how many survived, and the payment received for this activity.

\section{Descriptive statistics and empirical strategy}

\subsection{Descriptive statistics}

Table 1 summarizes key baseline variables from the PFO survey and satellite data and tests for balance between the treatment and control groups. The first two columns report variable means and standard deviations for the treatment and control subsamples, and the third column reports the normalized difference in means (treatment mean minus control mean, divided by the pooled standard deviation).

Regarding balance, none of the 18 variables tested has imbalance at the $10 \%$ signifi-

cance level. Also, the magnitudes of the normalized differences are small, well below the conventional threshold for imbalance of 0.25 (Imbens and Wooldridge, 2007). 
PFOs, on average, are 47.5 years old and have 8 years of education. The next variable listed is the self-reported "log" of the land area owned by the PFO. The variable uses the inverse hyperbolic sine transformation, which approximates the log function but accommodates zeros. In levels, the mean (median) land area for the sample is 10.8 (5.3) hectares.

About $85 \%$ of PFOs report having cut trees in the three years preceding the baseline survey. There are two broad reasons to cut trees. One is because the tree products are valuable. Large trees can be converted into lumber, medium-sized or crooked trees can be burned to make charcoal, or small trees can serve as building material for huts. Most of the trees for lumber and charcoal are sold to timber and charcoal dealers and feed into a national market, with much of the end use in urban areas. The second reason to cut trees is because the cleared land can then be used for other purposes, almost always cultivation in this setting. About $24 \%$ of our sample had deforested to use the land for cultivation, and $71 \%$ had done so to use or sell the timber products. PFOs often cut down and sell trees for emergency cash to pay for unexpected costs such as hospital bills or large, infrequent expenses such as school fees. About a quarter of the sample reports having done so. On average, revenue from timber products in the previous year is 110,000 UGX or $\$ 44$.

The baseline survey asked several other questions related to land and conservation. About $18 \%$ of the sample rented out part of the land they owned. One in ten were currently involved in an environmental program, a little more than half agreed that deforestation was a problem in the community, and a small number (5 percent) agreed with the statement that it is necessary to damage the environment to improve one's life. (Not surprisingly, this small minority has very low program take-up.)

The next rows summarize variables based on the satellite imagery. The amount of area classified as tree-covered in the PFO's land circle averages 4.1 hectares, which represents about one fifth of the land area. The average percent change in photosynthetic vegetation in the pre-intervention period from 1990 to 2010 is $3.6 \%$.

While our survey sample comprises only PFOs, anecdotally, PFOs are richer than nonPFOs in their village. Consistent with this, among PFOs, we find that the larger the amount 
of forest owned, the higher baseline per capita income is. Thus, this program, by virtue of targeting landowners, is regressive within the community (but progressive on a global scale because funds were being transferred from international donors to a developing country).

\subsection{Empirical strategy}

Using the data described above, we estimate the following equation via ordinary least squares regression to quantify the impacts of the PES program:

$$
\text { TreeCover }_{i j}=\alpha+\beta \text { Treat }_{j}+\gamma \text { BaselineTreeCover }_{i j}+X_{1 i j} \cdot \delta+X_{2 i j} \cdot \mu+\varepsilon_{i j} \text {. }
$$

The outcome is the amount of tree cover at endline on the land owned by PFO $i$ in village $j$ after the intervention has been in place for roughly one and a half years. As a proxy for the land owned by the PFO, we use a circle of land surrounding his home. The regressor of interest is Treat which equals 1 in the treatment villages and 0 in the control villages. The coefficient $\beta$ is the effect of the PES program, which is hypothesized to be positive.

We control for baseline tree cover as well as the vector $X_{1}$, which encompasses variables related to our stratification procedure, in all specifications. $X_{1}$ comprises subcounty fixed effects, as the randomization was stratified by subcounty, and the village-level variables we sought baseline balance on in our randomization: number of PFOs, average household earnings per capita, distance to a road, and average land size (Bruhn and McKenzie, 2009). $X_{2}$ are additional control variables we include in our preferred specification, namely 1990 and 2010 measures of vegetation on the PFO's land, based on Landsat images (to control for any pre-trends in deforestation) and dummy variables for the date of the baseline satellite image. Because the treatment varies at the village level, we adjust for non-independence of errors within a village, i.e, we cluster on village.

In the regressions, we weight observations by the proportion of the PFO's land with non-missing satellite data. As described in the previous section, because of cloud cover (and to a lesser degree because of land lying outside village boundaries), in the estimation sample we have data for on average $79 \%$ of the land circle. The proportion varies from less than 
$1 \%$ to over 99\%; the histogram is shown in Appendix Figure A2. In essence, we have an aggregate outcome variable measured with a sampling rate that varies by observation, so to improve efficiency we weight by this sampling rate (Solon, Haider, and Wooldridge, 2015).

We also estimate a model where the outcome is the change in tree cover between baseline and endline, i.e., that modifies equation (1) by constraining $\gamma$ to be equal to 1 . In addition, we estimate proportional effects using the inverse hyperbolic sine (IHS) transformation, which approximates the log function but is defined at 0 (Burbidge, Magee, and Robb, 1988). We also show results where the unit of observation is the village.

In addition, we examine survey-based outcomes, estimating an equation analogous to (1). We control for the baseline outcome in cases where it was collected. We include a dummy variable for observations with missing baseline values, and impute the baseline value to be the sample mean for those observations.

\section{Impacts of the PES program}

\subsection{Program take-up}

Of the 564 PFOs in our sample in treatment villages, 180, or 32\%, enrolled in the PES program. In addition, 6 PFOs in control villages (1\%) enrolled; they resided in control villages but owned forest in treatment villages. Sampling and assignment to treatment were based on the village of residence, but CSWCT allowed a PFO to enroll any land located in a treatment village. Table 2, column 1, estimates the effect of treatment on take-up as a regression; residing in a treatment village increases take-up by 31.9 percentage points.

Column 2 reports the treatment effect on PES payments (the total payments over the two years), which was 90,000 UGX, or $\$ 36$. (In the tables, monetary amounts are reported in units of 10,000 UGX, which is \$4). Thus, per PFO who enrolled, the average payment was $\$ 113(\$ 36 \div 31.9 \%)$. Most of these payments $(89 \%)$ were for avoided deforestation, with the balance for reforestation. On average, a treated PFO received $25.4 \%$ of the amount he was eligible for (column 4), implying that enrollees earned on average $80 \%$ of their eligible amount. Some enrollees violated the contract and received no payment, some fully complied 
and received $100 \%$, and some partially complied (e.g., their seedlings died) and they received partial payment, at the discretion of CSWCT ${ }^{14}$

It is surprising that program take-up was so low. Enrollment confers option value to the PFO, even if he is unsure whether he wants to comply; if he then does comply, he will receive money, and if he does not, while he receives no payment, there is also no punishment. Moreover, with imperfect monitoring, there is a chance of a false positive in which the PFO deforests, CSWCT assesses that he complied, and he gets paid.

To better understand why take-up was low, the endline survey asked treatment-village PFOs why they did or did not sign up for the program. The overwhelming reason for lack of take-up is mundane: Two thirds of PFOs who did not enroll were unaware of the program or did not know what it was about (see Appendix Figure A1). CSWCT's marketing efforts did not succeed in informing all PFOs about the program. Similarly, the logistics of enrolling were a barrier to enrollment. CSWCT collected the signed contracts on a particular day in each village, and if a PFO was unaware of this process or absent that day, he missed, or at least thought he had missed, his chance to enroll. Together, these reasons account for $77 \%$ of non-enrollment. These implementation problems could likely be addressed in future PES programs, leading to higher take-up.

About $11 \%$ of non-enrollment is due to more fundamental reasons. Many PFOs found the PES contract complex and difficult to understand. In particular, many were worried that the contract might be a ploy to grab their land. While in future programs it might be possible to explain the PES contract more thoroughly to PFOs and assuage their concerns, this barrier to enrollment is rooted in lack of formal property rights, concerns about theft and corruption, and low levels of education, factors which are common in many of the low-income settings amenable to deforestation PES programs. The remaining $12 \%$ of nonenrollment is because the PFO preferred deforesting to the financial incentives so simply was not interested; CSWCT deemed him to not have eligible forest; or miscellaneous reasons.

Besides asking PFOs why they did not take up the program, we can also use the base-

\footnotetext{
${ }^{14}$ In unreported results, we find that enrolling in the PES program did not crowd out participation in other environmental programs. No comparable program was offered in the area at the time.
} 
line data to assess the determinants of take-up. Few PFO characteristics predict take-up, as shown in Appendix Table A3, which is consistent with take-up being largely related to supply factors such as marketing rather than demand. Four of the characteristics we examine are significantly correlated with take-up. PFOs with more land, and less tree cover conditional on land owned, are more likely to enroll. In addition, PFOs who had cut trees for emergency or lumpy expenses recently were less likely to take up the program; as discussed by Jayachandran (2013), a limitation of PES programs that offer a steady stream of payments to preserve forest (or other environmental assets) is that even if the net present value of the payments exceeds the revenue from selling the timber, liquidity-constrained PFOs might choose immediate money over future PES payments. Also, the small minority who believe it is necessary to damage the environment to improve life have much lower take-up.

Finally, we test whether take-up is systematically higher for those with lower counterfactual deforestation. To do so, we use the control group and regress the change in tree cover on the variables in Appendix Table A3, column 1, and use the results to calculate the predicted change in forest cover for treatment PFOs. Column 4 shows that take-up of the program is unrelated to predicted deforestation, again suggesting no selective take-up by those who would have anyway kept their forest intact 15

\subsection{Remote-sensing results}

\subsubsection{Impacts of the PES program on forest cover}

The main results of the paper are presented in Table 3. Here we examine the effect of the PES program on tree cover. All columns control for the baseline value of the outcome and stratification controls (subcounty fixed effects and village-level variables that were balanced before randomization). Column 2 onward additionally control for the area covered by photosynthetic vegetation in 1990 and 2010 and dummy variables for the date of the baseline satellite image.

As context for interpreting the treatment effects, it is valuable to first understand the

\footnotetext{
${ }^{15}$ The predicted change in tree cover has a standard deviation of 1.05 , so the coefficient implies that when the variable is one standard deviation lower (i.e., more deforestation), take-up is 2.6 percentage points lower.
} 
business-as-usual patterns of deforestation. In the control group, the average tree loss per PFO between baseline and endline is 0.35 hectares, which is $8.7 \%$ of baseline tree cover. This corresponds to $5.8 \%$ loss per year. Note that this rate of tree loss is higher than most estimates of Uganda's rate of forest loss, which are based on changes in the edge of the forest. Our high-resolution data detects additional loss of trees due to selective tree-cutting within the forest, i.e., forest degradation.

Column 1 shows that the PES program caused an increase in tree cover at endline, relative to the control group, of 0.25 hectares per treatment PFO. The treatment group experienced net tree loss, but significantly less than the control group. Column 2 adds in control variables for pre-baseline vegetation, and the results are similar; the effect size is 0.27 hectares.16 This effect is statistically significant at the $5 \%$ level. This is our main specification, which we use later in the paper for heterogeneity and cost-benefit analyses.

The coefficient on the baseline forest cover variable is close to 1, which is not surprising because a tree that is not cut down or does not die will grow a bit over two years, but is largely persistent. As such, the estimates are similar when estimated in changes (column 3).

The magnitude of the treatment effect represents over half of their baseline to endline decrease in tree cover. This effect size is large, even larger than the take-up rate (although we cannot statistically reject that the effect size is the same as or less than the take-up rate). This suggests that the payments were not simply inframarginal to behavior, and, in fact, those who took up the program would have deforested more than the typical PFO, absent the program, which is quite surprising.

One partial explanation for the large effects is that some non-enrollees thought they were enrolled in the program, and these PFOs might have avoided deforestation based on an incorrect belief that they would be paid if they did so ${ }^{17}$ In the endline survey, we asked the

\footnotetext{
${ }^{16}$ The unreported coefficient on 2010 vegetation is positive, and the coefficient on 1990 vegetation is very similar in magnitude and negative, both with p-values $<0.01$. These patterns indicate that, first, the Landsat vegetation variable provides additional information on baseline tree cover, and, second, vegetation loss in the two decades prior to the study is predictive of a loss in tree cover over the study period.

${ }^{17}$ These could be cases where the PFO misunderstood the procedure to enroll or where CSWCT made a mistake in not registering their contract. In any case, they did not receive any monitoring or payments, according to CSWCT's records.
} 
treatment group if they were enrolled in the program. Of the 384 non-enrollees, 46 reported being enrolled. Meanwhile, 20 of the 180 actual enrollees (those who enrolled according to CSWCT's records), reported that they were not enrolled. Thus, self-reported take-up was 5 percentage points $((46-20) / 564)$ higher than official take-up. Note that these patterns could be due to measurement error in our survey data rather than PFO misperceptions.

In addition, a small part of the tree gain could be from the reforestation component of the program. On average 0.1 hectare was set aside for reforestation per treated PFO, although the number of surviving trees per PFO was only 10, as shown in Appendix Table A4. Seedlings would not have grown large in two years, but suppose each had a crown area of 5 square meters or 0.0005 hectares (which is likely an overestimate). This would mean that reforestation explains 0.005 hectares of the forest gain.

Another possible effect that would increase the effect size is if the program had positive spillovers to non-enrollees in treatment villages. For example, village norms about treecutting or about barring others from taking trees from one's land might have changed.

\subsubsection{Robustness of the results}

The appendix presents several robustness checks on the main results. Appendix Table A5 examines proportional effects on tree cover using the IHS transformation. The treatment caused a $4.4 \%$ increase in tree cover, which represents about $61 \%$ of the $7.3 \%$ average reduction in tree cover in the control group. Note that this deforestation rate in the control group and proportional treatment effect size are somewhat smaller than when estimated in levels, implying that PFOs with a larger amount of baseline tree cover have a higher rate of deforestation and larger proportional treatment effect.

Appendix Table A6 shows unweighted results, which do not take into account the extent of missing remote sensing data. The results are similar to the main results.

Appendix Table A7 addresses the skewness of the land area distribution by dropping the top $1 \%$ of PFOs in terms of baseline forest cover. (The results are similar when dropping outliers in terms of endline forest cover or baseline land ownership). Not surprisingly, the results in levels are smaller in magnitude than in the main results, but remain statistically 
significant. The effect size corresponds to deforestation being $57 \%$ lower in the treatment group than in the control group. The last three columns of Appendix Table A7 use equallysized land circles for each PFO that are based on the median land area in the sample, as an alternative approach to ensure that large PFOs are not driving the result. In addition, PFOs' self-reports on land area are often inaccurate, and using the median size removes this noise (but also removes signal to the extent they are accurate). The median circles are on average smaller (because of the skewed distribution), and the magnitudes of forest cover in both the treatment and control group are smaller in levels, but the proportional change in forest cover is similar to the main results.

Appendix Table A8 estimates the effects using alternatively-sized land circles. The first three columns show the results using circles whose area is the PFO's land area; unless the PFO's landholding is exactly a circle centered on his home, these circles will omit much of their land. We continue to find statistically significant treatment effects, though not surprisingly, the amount of tree gain in hectares is smaller; the circles are half the size, and the coefficient is $56 \%$ of the size, suggesting that these circles are too small to encompass the area where the program is having impacts. The next three columns show the results using circles that are 3 times as large as the PFO's land area. Again, we find positive, statistically significant impacts on tree cover. While these circles are $50 \%$ larger than our main specification, the treatment effect is only $31 \%$ larger, which suggests that circles twice as large as the landholding encompass most of the PFO's land and the area where the treatment effects occur.

As described in the data section, we placed an order for the baseline QuickBird images in May 2011, requesting that the study region be imaged as soon as possible. The majority of the region was imaged in May and June, but some of the area was not imaged until December 2011. The subcounty lotteries occurred between August and December 2011, which means the baseline image was taken after randomization in some cases. Hence, our arguably most important robustness check is to restrict the sample to cases where the subcounty lottery occurred after the date of the baseline satellite image. When we do so, we continue to 
find positive, statistically significant effects on tree cover, as shown in Appendix Table A9. The time span between baseline and endline images is longer in this subsample compared to the full sample (because we have dropped observations with late baseline data), so with a constant rate of deforestation, more deforestation should occur in the control group in this subsample, and, likewise, more deforestation should be averted in the treatment group. Indeed, we find a larger treatment effect than in the full sample, as well as a higher amount of deforestation in the control group.

In summary, the results are robust to various potential concerns about the estimation.

\subsubsection{Threats to validity}

One concern in interpreting the treatment effect on tree cover is that PFOs might have simply shifted their deforestation to other land. The results presented above are net of several potential forms of such leakage. First, if PFOs preserved the land that CSWCT classified as forest and that was regulated under the PES contract but cut down other patches of trees on their land, our results measure the net effect because they examine the entire land owned by PFOs rather than just their natural forest. Second, the fact that the land circles we examine are larger than the land owned means we incorporate increased tree-clearing on nearby land as well. Third, there could be within-village shifting from one PFO to another. The low take-up rate suggests there was ample scope for this behavior; one way to game the PES program is for two PFOs to agree that one will enroll, the other will not, and they will do their joint tree-clearing on the non-enrollee's land. (Only one treatment village had $100 \%$ take-up). If the PFOs who engaged in this behavior are in our sample, then we also incorporate this type of shifted tree-clearing through our intent-to-treat estimates.

Our PFO-level results, however, do not net out displacement of deforestation to others in the village who are not in our sample. To examine this potential concern, we also estimate village-level effects. By village-level, we do not mean that we sum up to the village level the land circles for the PFOs in our sample, but rather we use the entire area of the village, as defined by government boundaries. The last two columns of Table 3 present these results. While we have considerably less statistical power in this analysis, the treatment effects 
are positive and marginally significant when estimated in changes (column 5) ${ }^{18}$ To assess whether there are within-village spillovers, we can compare the village-level point estimate to the PFO-level estimate. Column 4 indicates a 4.31 hectare aggregate gain in tree cover per treatment village. In the analogous PFO-level specification (Table 3, column 2), we estimated a 0.273 hectare increase per PFO. We have on average 9.1 PFOs per village in our sample, but this underestimates the number of eligible PFOs because some did not complete our baseline survey. Our census identified 12.0 PFOs per village, and multiplying this number by the PFO-level effect of 0.273 gives an aggregate effect of 3.27 hectares per village. The signature of within-village displacement would be if this 3.27 hectare effect among PFOs were larger than the village-level effect based on the boundaries of the village. Instead it is similar to and in fact smaller than the village-level estimate of 4.31 hectares.19 Thus, we find no evidence that tree-cutting merely shifted within the village.

PFOs who lived near government forest reserves had an additional option to (illegally) take more trees from the reserves. However, Appendix Table A10, columns 1 and 2, which examine treatment effect heterogeneity based on distance to the forest reserves or the village being contiguous to the forest reserves (which applies to 17 of the 121 villages) show no evidence of this behavior. To recap, we find no evidence of PFOs simply shifting their deforestation within-person or within-village or to government forest reserves, which suggests the PES program in fact led to additional forest cover.

Another possibility that would bias the results is if the program had spillover effects on control villages. The results would be biased upward if the program increased deforestation in the control group. For example, treatment PFOs might have sought trees from control villages (although this seems unlikely given that there was untapped potential to procure trees from non-enrollee PFOs within their village). A more likely form of spillover is higher demand in control villages from outside timber dealers because supply had dried up in

\footnotetext{
${ }^{18}$ The lower power is not surprising given that the land owned by the PFOs in our sample comprises, on average, only $21 \%$ of the total land in the village.

${ }^{19}$ Instead of scaling by eligibility, one can also scale by the percent of program enrollees who are in our sample, which is $60 \%$. Applying this scale factor to our PFO-level results predicts a 4.13 hectare gain in tree cover per village, which is again smaller than our actual village-level estimate.
} 
treatment villages. Another possible spillover is that the control group was upset about not receiving the program and reacted by deforesting more than usual. To test for these three mechanisms, we examine whether there is greater tree loss in control villages that are closer to treatment villages. We find no evidence of such spillovers, as shown in Appendix Table A10, column 3. While this test sheds light on local spillovers, it does not assess if there were region-wide effects. For example, there could be an aggregate increase in demand for timber in all of our control villages caused by the PES program. The study region feeds into a national timber market, and the PES program was relatively small, so the program seems unlikely to have had large general equilibrium effects, although such effects would be more pertinent if the program were scaled up. Even though we cannot identify price effects that are aggregate to our study region, we did ask questions on the endline survey about visits by timber dealers. Columns 4 and 5 of Appendix Table A10 show that there was no increase in visits by timber dealers in control villages relative to treatment villages.

Of course, the reduction in deforestation in the study region might also be offset by increases outside the region. The premise of this and other PES programs is that demand for timber products is not fully inelastic, so program effects will not just be undone elsewhere. People will reduce consumption or substitute toward options with a lower carbon footprint. For example, if PFOs clear less forest for subsistence farming, their demand for food might be met by farms with much higher agricultural yield.

A different type of concern is related to PFOs' expectations. PFOs were told that the program would last for two years, and the study results might or might not lead to program continuation and expansion in a few years. In the control group, behavior might not reflect "business as usual" if PFOs anticipated getting the program in the future. A priori, these anticipation effects could go in either direction. Perhaps PFOs who thought it was likely the program would come to their village kept their forest intact to be eligible for the program (which would bias the estimates toward 0), or perhaps they wanted to deforest while they could (bias away from 0). Similarly, the impacts in the treatment group might vary with their expectations. Some PFOs might have thought the program would last forever, and because 
non-compliers were not allowed to rejoin the program later, this misperception about the program horizon would have raised the valuing of complying in the short run. The last two columns of Appendix Table A10 examine these possible effects due to expectations. First, we examine whether deforestation in the control group varies with whether the PFO thinks the program will come to his village, which we asked on the endline survey in control villages. Second, we examine whether the program effects are larger for PFOs in the treatment group who think the program will last longer than it actually did; we asked this question on the endline survey in treatment villages. We do not find evidence that either of these types of expectations affected how much PFOs deforested.

\subsubsection{Heterogeneous impacts}

Having shown the average treatment effects, we next examine heterogeneity in the effects by baseline characteristics. We first analyze how the effects vary with the initial amount of forest. The direction of this heterogeneity is not clear a priori. On the one hand, those with more forest have more potential forest to keep intact, which could lead to larger program impacts. On the other hand, the fact that more of their forest is intact suggests they may have deforested less in the past, so they might have lower counterfactual tree-cutting and smaller program effects. We find that the first of these possibilities is more relevant: Tree gain is larger for PFOs with more tree cover at baseline (Table 4, column 1). Column 2 shows this same pattern holds using the proportion of land that is tree-covered.

The next four columns examine heterogeneity by whether and why the PFO reported clearing trees recently. Those who had cut trees recently exhibit larger treatment effects, and this seems to be more true for those who cut trees for timber products as opposed to cultivation. Column 6 shows that, despite the lower take-up among those who cut trees for emergency or lumpy expenses discussed earlier, the intent-to-treat effect on forest cover seems to be larger for them (but statistically insignificantly). Column 7 shows that the higher the revenue from timber products at baseline, the larger the treatment effect.

The pattern seen across the first seven columns is that if a characteristic is predictive of more deforestation in the control group between baseline and endline (negative main effect of 
Characteristic), it is also associated with more averted deforestation in the treatment group (positive interaction effect). Column 8 tests for this pattern more comprehensively. Using the control group, we regress the change in tree cover on several baseline characteristics (the same ones used to predict take-up in Appendix Table A3). We then use the results to calculate the predicted change in forest cover for both control and treatment PFOs ${ }^{20}$ The negative interaction effect in Column 8 indicates that the PES program caused larger gains in forest cover for treated PFOs whose forest loss, absent the program, would have been larger. This pattern reaffirms what earlier results suggested: To first approximation, enrollment in the program was unrelated to predicted counterfactual deforestation, enrollees complied and refrained from deforesting, and as a result, the largest program impacts are seen for those who would have deforested the most had the program not been offered to them.

\subsection{Household survey results}

We now turn to examining outcomes using the endline household survey data.

\subsubsection{Self-reported tree-cutting and other behaviors related to land}

Self-reports by PFOs corroborate the remote-sensing result that the intervention reduced deforestation. As seen in Table 5, treatment group PFOs are less likely to have cut any trees in the past year. An important caveat is that PFOs might have given inaccurate answers, for example if enrollees thought that admitting to tree-cutting on the survey would jeopardize their PES payouts.

Attrition from the endline survey was higher in the treatment group than in the control group, and in particular, treated PFOs who did not take up the program were less likely to participate in the survey. As such, attrition likely biases upward the magnitude of the treatment effects. We therefore also present Lee bounds on the treatment effects for the survey results. The lower-magnitude bound provides a conservative estimate of the effect ${ }^{21}$ Table

\footnotetext{
${ }^{20}$ The predicted value used as the regressor for control group observations is estimated excluding that observation itself to avoid bias (Abadie, Chingos, and West, 2013).

${ }^{21}$ Lee bounds make a monotonicity assumption about attrition: Treatment status affects selective attrition in only one direction. With more attrition in the treatment group, the upper (lower) bound assumes that selective attrition in the treatment group is by those with high (low) outcome values, and thus trims observations in the control group with high (low) outcomes such that the attrition rate is equalized between
} 
5. column 1, shows that the point estimate for cutting any trees is -0.14 in the untrimmed sample, and the smaller-magnitude Lee bound is -0.10 .

Deforestation to clear land for cultivation and to obtain timber products both seem to have decreased, although there are wide bounds on these estimates. Columns 5 to 7 show that in the treatment group, total revenue from timber products is lower by 2.89 million UGX (\$116), or $23 \mathrm{log}$ points, and there is a 4 percentage point (27\%) lower likelihood of receiving any revenue from timber in the past year. These point estimates are based on the untrimmed sample and are suggestive, but the Lee bounds indicate that we cannot say anything conclusive about these outcomes.

Complying with the PES contract entails reducing one's own tree-cutting, but in our context, where others are given access to forest or might encroach on it, complying also means ensuring that others do not clear trees on one's land. As seen in Table 6, there is a roughly one third drop in the likelihood of allowing people to gather firewood from the forest (even though gathering fallen wood was allowed under the contract). There is no significant decrease in access granted to others who take trees from the land (though the point estimate is suggestive of such an effect). The program significantly increased how much PFOs patrol their land, as seen in column 3. While preventing illegal activity, in principle, should be done by the state, this role often falls to the individual in this context. PFOs have a private incentive to prevent theft of their forest even absent the PES program, but the program seems to have increased the value of doing so and induced more patrolling. Treatment PFOs did not respond to the program by fencing their land, however.

A reduction in others' right to gather firewood and access PFOs' land is very likely a regressive effect. In our study region, it is the norm for landowners to let poorer neighbors gather firewood or very small trees ("poles") for building material. Thus, the program could have had a negative impact on non-forest-owners, unless PFOs found some other way to make transfers to their poorer neighbors.

Interestingly, the program also seems to have affected perceived property rights: Treated groups (Lee, 2009). 
PFOs are more likely to report that their ownership of their forest strengthened in the past two years, though the point estimate is small and the lower bound estimate is insignificant (column 5). The program neither increased nor decreased disputes with neighbors about land (column 6).

\subsubsection{Socioeconomic impacts}

The last set of survey outcomes we examine is related to economic well-being. In principle, the program could have either increased or decreased current income. The PES payments could have enriched PFOs, or they could have tolerated a reduction in current income in exchange for wealth accumulation in the form of intact forest. In any case, the net effect is unlikely to be large in magnitude. The payment levels were chosen to be of the same order of magnitude as monetary opportunity costs, and the treatment caused a reduction in deforestation so payments were not inframarginal to behavior. Thus, it seems unlikely that the program would lead to a large increase in income, except perhaps for those with a particularly low opportunity cost, where a smaller payment would have sufficed to induce their reduction in deforestation, leaving them with inframarginal cash on the intensive margin. At the same time, because take-up was voluntary, decreases in permanent income are unlikely, and credit constraints or impatience probably prevented most PFOs from incurring a large decrease in current income, even if the value of their forest assets increased.

Measuring income is difficult because most individuals are self-employed or casual laborers, so we use expenditures as a proxy for current income. Table 7 , columns 1 to 3, examine spending in three broad categories: food, non-food, and alcohol and tobacco. The survey asked about spending in the past 30 days or 6 months in several finer categories, and we aggregated the data after harmonizing the lookback period. We do not find strong evidence of either an increase or decrease in expenditures. Non-food spending shows a positive effect but the lower bound effect is insignificant; the point estimate of a $5.3 \%$ increase is equivalent to 10,900 UGX (\$4.35) per month. Column 4 examines the respondent's self-reported status on a 9-point income ladder, relative to his community. The point estimate is suggestive of an increase in self-reported relative income, but the result is not particularly strong. 
Another effect the program might have had was on borrowing. Those who would have cleared trees for large spending needs might have switched to taking out loans, or if the program increased current income, it could have, in turn, decreased the need to borrow. We find no impact on loans (column 5). Finally, columns 6 and 7 examine two measures of child health, malaria and diarrhea. We find some suggestive evidence that the program decreased the self-reported rate of child diarrhea. Overall, we interpret the results in Table 7 as providing weak evidence that the program may have had some, but not major, positive effects on economic well-being of eligible PFOs and stronger evidence that it did not significantly decrease their economic well-being.

\section{Cost-effectiveness}

We next convert the program's effect on tree cover into averted $\mathrm{CO}_{2}$ emissions, calculate the monetary value of the averted emissions, and compare this benefit to the program costs.

\section{Amount of delayed $\mathrm{CO}_{2}$ emissions}

The program averted 0.268 hectares of deforestation per PFO eligible for the program. This estimate uses our intent-to-treat gain in tree cover from our main specification (Table 3. column 2) and subtracts 0.005 hectares potentially due to reforestation ${ }^{22}$ The average duration from baseline to endline was 1.5 years, but the payment data we use are for 2 years of compliance. To be conservative, we ignore the fact that the amount of averted deforestation likely accumulated during the remaining half year of the program.

We use Global Forest Map satellite-based estimates of biomass in forests, available at a 30 -meter resolution, to estimate the biomass and carbon in forestland in our study villages; the average is 153.5 tons of carbon per hectare (World Resources Institute, 2016).23 The carbon stored in other vegetation (e.g., agricultural cultivation) is negligible compared to trees, so this amount also represents the change in carbon stocks from tree-clearing (Houghton, 2007). To be conservative, we ignore the flow of carbon that trees absorb, assuming the

\footnotetext{
${ }^{22}$ We ignore the $\mathrm{CO}_{2}$ that the newly planted trees absorb during the intervention, as the amount is small.

${ }^{23}$ This value is the carbon per hectare of forest with at least $67 \%$ tree cover whereas our effect size is in hectares of tree cover, so we might be underestimating the carbon stored per hectare of tree cover.
} 
forest is close to carbon-neutral if it remains intact.

Combining these numbers, averted carbon per eligible PFO is 41.1 tons. Equivalently, the averted $\mathrm{CO}_{2}$ is 150.7 tons. ( $\mathrm{A} \mathrm{CO}_{2}$ molecule is 3.67 times as heavy as a carbon atom.)

\section{Program costs per ton of delayed $\mathrm{CO}_{2}$ emissions}

The average payment per PFO (inclusive of payments for reforestation) is $\$ 37.70$ over the two years of the program. 24 Thus, the program paid $\$ 0.25$ ( $\$ 37.70 \div 150.7$ tons) to delay each ton of $\mathrm{CO}_{2}$ emissions ${ }^{25}{ }^{26}$ We assume this full amount is a program cost, but note that payments in excess of the amount required to gain compliance are not true economic costs.

Payments to PFOs are not the only program cost. There are also costs for monitoring enrollees' forests and for program administration. Monitoring costs were $\$ 88$ per program enrollee, or $\$ 28$ per eligible PFO 27 We assume an additional cost per eligible PFO of $\$ 30$ for marketing of the program and overall program management. We further assume a $10 \%$ transaction fee for PES payments. Combining these assumptions, the administrative costs amount to $\$ 0.41$ per averted ton of $\mathrm{CO}_{2}$.

The monitoring costs could be considerably lower at scale-up because, for the sake of the randomized trial, the program was rolled out in a geographically dispersed set of villages. It seems reasonable that with greater geographic density, monitors could conduct 2 rather than 1 spot check per day ${ }^{28}$ In this case, the administrative costs of the program would be $\$ 0.32$ per averted ton of $\mathrm{CO}_{2}$.

Thus, our best guess of the total program costs at scale-up-incentive payments plus administrative costs - is $\$ 0.57$ per averted ton of $\mathrm{CO}_{2}$.

\footnotetext{
${ }^{24}$ This number is slightly higher than our full-sample estimate of $\$ 36$ (Table 2, column 2). The estimate of impacts on tree cover is based on the 995 PFOs with non-missing remote sensing data, and their forest area is slightly larger than average because small land circles are more likely to be fully cloud-covered. The average payment among the subsample with non-missing remote sensing data is $\$ 37.70$.

${ }^{25}$ One might want to include potential payments to the net $5 \%$ of non-enrollees who thought they had enrolled but were not paid. Scaling up by $(32 \%+5 \%) / 32 \%$ yields $\$ 0.29$ in payments per ton of $\mathrm{CO}_{2}$.

${ }^{26}$ If we use our village-level instead of PFO-level estimates for this calculation, we find a lower cost: $\$ 0.19$ in payments per averted ton of $\mathrm{CO}_{2}$.

${ }^{27} \mathrm{CSWCT}$ hired forest monitors who each covered 30 enrollees. Monitors were paid $\$ 90$ per month, and for transportation, were given on average two bicycles each. Adding in repair costs, the bicycles cost $\$ 480$ per monitor over the course of the program.

${ }^{28} \mathrm{~A}$ forest monitor was supposed to conduct 1 spot check every one or two months per PFO; at once per 6 weeks, he conducted slightly fewer than 1 spot check per day, assuming 25 work days per month.
} 


\section{Social benefit per ton of delayed $\mathrm{CO}_{2}$ emissions}

The amount paid to avert carbon emissions can be compared to the "social cost of carbon" or SCC (which is, more precisely, the social cost of $\mathrm{CO}_{2}$ ). The middle estimate used by the United States EPA for 2012 is $\$ 39$ (in 2012 USD) ${ }^{29}$

The SCC represents the benefit of permanently averting carbon emissions. While this program was intended to be a prototype of what could be a permanent program, it only ran for two years. The program effects we estimate represent a delay in tree-cutting. To quantify the delay length, we need to make assumptions about deforestation after the program ended, which we do not have direct measurements of. Our base case scenario assumes that PFOs deforest at a 50\% higher rate than usual after the program ends until they catch up on all their postponed deforestation, thus undoing the 2 years' worth of treatment effects over 4 years. The average delay in deforestation in this scenario is 3 years, assuming a uniform rate of deforestation. We also consider two more extreme scenarios. First, we assume PFOs catch up on all their delayed deforestation immediately when the program ends, in which case the benefits are for a delay of, on average, 1 year. Second, we assume PFOs resume their normal rate of deforestation after the program ends, rather than an accelerated rate; this is equivalent to a permanent two-year delay in both the deforestation that would have occurred during the intervention as well as all later deforestation 30

When a tree is cleared, its carbon is not all immediately emitted into the atmosphere. We assume that the average lag between tree-cutting and carbon emissions is 10 years ${ }^{31}$ The value of avoided future emissions depends on both the discount rate (which decreases the value) and the growth rate of the SCC (which increases the value). We use $3 \%$ for the

\footnotetext{
29 This value is the average SCC across the three integrated assessment models used by the US Environmental Protection Agency (EPA), and assumes a discount rate of 3\%, which is the EPA's median scenario. The SCC for 2010 and 2015 are $\$ 33$ and $\$ 38$ in 2007 US dollars (USD); interpolation gives a SCC for 2012 of $\$ 35$ in 2007 USD, or $\$ 39$ per metric ton of $\mathrm{CO}_{2}$ in 2012 USD.

${ }^{30}$ We assume that PFOs clear their forest at the same rate we observe between baseline and endline $(8.7 \%$ of their stock of trees every two years) until their forest is depleted. The amount of deforestation that is delayed for two years, discounted back to the present, is 2.55 hectares per PFO, or 9.4 times the amount observed during the intervention.

${ }^{31}$ The exact time profile depends on many complex factors and is beyond the scope of this paper. A 10-year delay is consistent with $45 \%$ of the biomass being burned with immediate release, $45 \%$ decomposing with a mean survival of 15 years, and $10 \%$ being used as lumber with the carbon stored for 30 years.
} 
discount rate (the EPA's middle rate) and $1.9 \%$ for the growth of the SCC, based on EPA projections (Interagency Working Group on Social Cost of Carbon, 2013).

Putting these assumptions together, the discounted benefit of delaying a ton of $\mathrm{CO}_{2}$ 's worth of tree-cutting for our base case (treatment effects undone after 4 years) is $\$ 1.11$. The $\mathrm{CO}_{2}$ benefits are twice as large as the program costs.

If, instead, PFOs catch up on their backlog of avoided deforestation the moment the program ends, the benefit-cost ratio falls to 0.7. Alternatively, if PFOs resume deforesting at their typical rate after the program ends, the benefit cost-ratio rises to 12.3. This last scenario of a permanent two-year delay in deforestation is the relevant one for extrapolating to a longer-lasting program: If the program effects we observe over two years persist with a permanent intervention, the net present cost to permanently avert a ton of $\mathrm{CO}_{2}$ would be $\$ 3.10$, much less than the social cost of carbon. Note that this is a very tentative extrapolation. 32

Table 8 summarizes the PES program costs and benefits per ton of averted $\mathrm{CO}_{2}$ emissions for our base case, the two extreme scenarios discussed above, and several alternative scenarios. Note that these cost-benefit numbers have a wide confidence interval. Not only do we need to make assumptions about deforestation after the program end, but the amount of biomass in forests and the effect of the program on tree cover are measured with error. But these figures suggest that, under most assumptions, the program costs are lower than the social benefit of the delayed tree-cutting and $\mathrm{CO}_{2}$ emissions.

Another way to benchmark the program is to compare it to other environmental programs. Per ton of averted $\mathrm{CO}_{2}$, this program is considerably less expensive than most alternative policies in place in the US to reduce carbon emissions such as hybrid and electric car subsidies; per averted ton of $\mathrm{CO}_{2}$, those two policies cost 4 to 24 times as much as the carbon benefits they generate (Knittel, 2012; Gayer and Parker, 2013). Alternative programs in developing countries are also often cost-ineffective; for example, per ton of averted $\mathrm{CO}_{2}$,

\footnotetext{
${ }^{32} \mathrm{We}$ assume the payments needed to deter deforestation rise over time at the same rate as the SCC. The costs might rise faster than this rate if the opportunity cost of avoided deforestation is convex in the delay length or grows rapidly due to rising prices of timber products. The restrictions on tree-cutting in the PES contract were tailored to the two-year duration; one would likely want to modify the contract conditions for a longer-duration program.
} 
giving households incentives to upgrade their refrigerators and air conditioners in Mexico costs over 10 times the SCC (Davis, Fuchs, and Gertler, 2014).

A very important caveat is that these cost-benefit calculations do not quantify the carbon impacts of behavioral responses beyond tree-cutting in the study area. For example, how much less fuel do urban consumers use? What fuel sources do they substitute toward? Many of these impacts occur outside the study area and are beyond the scope of this study. In addition, while our analysis does not detect general equilibrium effects, such effects could be important if PES programs were implemented at large scale.

Beyond averted $\mathrm{CO}_{2}$, there are also other benefits of the program. For example, the program redistributes from the wealthy to the poor. While PFOs are not poor relative to their neighbors, they are poor in global terms. If funded through international carbon markets, PES program costs - both the payments to PFOs and even the administrative costs incurred by local organizations like CSWCT-would represent income distribution. We did not find large improvements in consumption for participants, but they accumulated wealth in the form of a more valuable forest, with no apparent loss to current income. Another benefit that we cannot quantify with our study design is increased biodiversity, for example through a higher likelihood of the chimpanzee population surviving. Biodiversity is valuable to society per se and, in the case of chimpanzees, boosts Uganda's tourism revenue.

On the opposite side of the ledger, the program has other costs besides program implementation costs. As seen in our survey results, one effect of the program was that PFOs gave their neighbors less access to their land to gather firewood. Most of those affected in this manner are the poorest, landless individuals in the community, and the program could have made them worse off. Moreover, even if the program did not decrease anyone's absolute wealth (inclusive of access to others' forest), it likely increased within-village inequality because those eligible for the program were relatively wealthy to begin with. 


\section{Conclusion}

This paper evaluated an important policy tool being used to mitigate climate change, namely Payments for Ecosystem Services in which financial incentives are given to keep forest intact. While the logic of using financial incentives to reduce deforestation is wellestablished, a concern with such a program is that many of the payments will be inframarginal to behavior, so the program will have minimal impact on deforestation per dollar spent.

We measure causal impacts of a PES program in Uganda through a randomized controlled trial in which 60 of 121 study villages received the two-year program. Using highresolution satellite images, we find that the program led to a sharp reduction in deforestation. Our cost-benefit calculations suggest that the program costs were less than the social benefit of the delay in $\mathrm{CO}_{2}$ emissions from deforestation that was generated by the program.

Thus, in this setting, PES was effective and did not suffer the problems of inframarginality or leakage that could potentially dampen its cost-effectiveness. Future research is needed to assess longer-term programs. It is possible that if PFOs learn that monitoring is imperfect or if their initial pro-environment motivations for complying fade, the impacts of the program would also fade. Nonetheless, we view our results as a proof-of-concept that PES programs can be a cost-effective way to avert deforestation in developing countries - and hence a powerful tool to mitigate climate change. 


\section{References}

Abadie, A., M. M. Chingos, and M. R. West (2013): "Endogenous Stratification in Randomized Experiments," Discussion paper, National Bureau of Economic Research.

Alix-Garcia, J., C. McIntosh, K. R. Sims, and J. R. Welch (2013): "The Ecological Footprint of Poverty Alleviation: Evidence from Mexico's Opportunidades Program,"

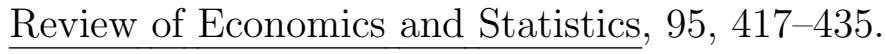

Alix-Garcia, J. M., E. N. Shapiro, and K. R. Sims (2012): "Forest Conservation and Slippage: Evidence From Mexico's National Payments for Ecosystem Services Program," Land Economics, 88(4), 613-638.

Arriagada, R. A., P. J. Ferraro, E. O. Sills, S. K. Pattanayak, and S. Cordero-Sancho (2012): "Do Payments for Environmental Services Affect Forest Cover? A Farm-Level Evaluation from Costa Rica," Land Economics, 88(2), 382-399.

Asner, G. P., D. E. Knapp, A. Balaji, and G. PÁez-Acosta (2009): "Automated Mapping of Tropical Deforestation and Forest Degradation: CLASlite," Journal of Applied Remote Sensing, 3(1), 033543-033543.

Assunção, J., M. Lipscomb, A. M. Mobarak, and D. Szerman (2014): "Electrification, Agricultural Productivity and Deforestation in Brazil," Discussion paper.

Benz, U. C., P. Hofmann, G. Willhauck, I. Lingenfelder, and M. Heynen (2004): "Multi-Resolution, Object-Oriented Fuzzy Analysis of Remote Sensing Data for GIS-Ready Information," ISPRS Journal of Photogrammetry and Remote Sensing, 58(3), 239-258.

Blaschke, T. (2010): “Object Based Image Analysis for Remote Sensing," ISPRS Journal of Photogrammetry and Remote Sensing, 65(1), 2-16.

Bruhn, M., And D. McKenzie (2009): "In Pursuit of Balance: Randomization in Practice in Development Field Experiments," American Economic Journal: Applied Economics, $1(4), 200-232$.

Burbidge, J. B., L. Magee, and A. L. RobB (1988): "Alternative Transformations to Handle Extreme Values of the Dependent Variable," Journal of the American Statistical Association, 83(401), 123-127.

Burgess, R., M. Hansen, B. A. Olken, P. Potapov, and S. Sieber (2012): "The Political Economy of Deforestation in the Tropics," Quarterly Journal of Economics, 127(4), $1707-1754$.

Canadell, J. G., ET Al. (2007): "Contributions to Accelerating Atmospheric $\mathrm{CO}_{2}$ Growth From Economic Activity, Carbon Intensity, and Efficiency of Natural Sinks," Proceedings of the National Academy of Sciences, 104(47), 18866-18870. 
Davis, L. W., A. Fuchs, And P. Gertler (2014): "Cash for Coolers: Evaluating a Large-Scale Appliance Replacement Program in Mexico," American Economic Journal: Economic Policy, 6(4), 207-238.

Desclée, B., P. Bogaert, and P. Defourny (2006): "Forest Change Detection by Statistical Object-Based Method," Remote Sensing of Environment, 102(1), 1-11.

Edmonds, E. V. (2002): "Government-Initiated Community Resource Management and Local Resource Extraction From Nepal's Forests," Journal of Development Economics, 68(1), 89-115.

Engel, S., S. Pagiola, And S. Wunder (2008): "Designing Payments for Environmental Services in Theory and Practice: An Overview of Issues," Ecological Economics, 64(4), 663-674.

FAO (2010): "Global Forest Resources Assessment 2010, Main Report," Food and Agriculture Organization of the United Nations.

Ferraro, P. J., M. M. Hanauer, D. A. Miteva, J. L. Nelson, S. K. Pattanayak, C. Nolte, and K. R. Sims (2015): "Estimating The Impacts of Conservation on Ecosystem Services and Poverty by Integrating Modeling and Evaluation," Proceedings of the National Academy of Sciences, 112(24), 7420-7425.

Ferraro, P. J., And A. Kiss (2002): "Direct Payments to Conserve Biodiversity," Science, 298(5599), 1718-1719.

Ferraro, P. J., and S. K. Pattanayak (2006): "Money for Nothing? A Call for Empirical Evaluation of Biodiversity Conservation Investments," PLoS Biology, 4(4), 482-488.

Fisher, B. (2010): "African Exception to Drivers of Deforestation," Nature Geoscience, $3(6), 375-6$.

Fiszbein, A., N. R. Schady, and F. H. Ferreira (2009): Conditional Cash Transfers: Reducing Present and Future Poverty. World Bank Publications.

Foster, A. D., And M. R. Rosenzweig (2003): "Economic Growth and the Rise of Forests," Quarterly Journal of Economics, 118(2), 601-637.

Gayer, T., And E. PArker (2013): "The Car Allowance Rebate System: Evaluation and Lessons for the Future," Economic Studies Policy Brief, Brookings Institution.

Greenstone, M., And T. Gayer (2009): "Quasi-Experimental and Experimental Approaches to Environmental Economics," Journal of Environmental Economics and Management, 57(1), 21-44.

Greenstone, M., And B. K. JaCK (2015): "Envirodevonomics: A Research Agenda for an Emerging Field," Journal of Economic Literature, 53(1), 5-42. 
Greenstone, M., E. Kopits, and A. Wolverton (2011): "Estimating the Social Cost of Carbon for Use in US Federal Rulemakings: A Summary and Interpretation," Discussion paper, National Bureau of Economic Research.

Hegde, R., And G. Q. Bull (2011): "Performance of an Agro-Forestry Based Paymentsfor-Environmental-Services Project in Mozambique: A Household Level Analysis," Ecological Economics, 71, 122-130.

Houghton, R. A. (2007): "Balancing the Global Carbon Budget," Annual Review of Earth and Planetary Sciences, 35, 313-347.

Imbens, G. (2011): "Experimental Design for Unit and Cluster Randomized Trials," Lecture notes prepared for International Initiative for Impact Evaluation.

Imbens, G. W., And J. D. Wooldridge (2007): "What's New in Econometrics," NBER Mini-Course Lecture Notes, Lecture 1.

Interagency Working Group on Social Cost of Carbon (2013): "Technical Update on the Social Cost of Carbon for Regulatory Impact Analysis under Executive Order 12866," United States Environmental Protection Agency Technical Support Document.

JACK, B. K. (2013): "Private Information and the Allocation of Land Use Subsidies in Malawi," American Economic Journal: Applied Economics, 5(3), 113-35.

Jack, B. K., P. Oliva, C. Severen, E. Walker, and S. Bell (2015): "Technology Adoption Under Uncertainty: Take-Up and Subsequent Investment in Zambia," Discussion paper, National Bureau of Economic Research.

Jayachandran, S. (2013): "Liquidity Constraints and Deforestation: The Limitations of Payments for Ecosystem Services," American Economic Review, 103(3), 309-313.

Knittel, C. R. (2012): "Reducing Petroleum Consumption from Transportation," Journal of Economic Perspectives, 26(1), 93-118.

LEE, D. S. (2009): "Training, Wages, and Sample Selection: Estimating Sharp Bounds on Treatment Effects," Review of Economic Studies, 76(3), 1071-1102.

NabuURs, G. J., ET AL. (2007): "Forestry," in In Climate Change 2007: Mitigation of Climate Change. Contributions of Working Group III to the Fourth Assessment Report of the Intergovernmental Panel on Climate Change, ed. by M. Apps, and E. Calvo. Cambridge University Press, New York, NY.

NEMA (2008): "The State of Environment Report for Uganda 2008: Sustainable Environment for Prosperity," Report, Uganda National Environment Management Authority.

Nordhaus, W. (2014): "Estimates of the Social Cost of Carbon: Concepts and Results from the DICE-2013R Model and Alternative Approaches," Journal of the Association of Environmental and Resource Economists, 1(1/2), 273-312. 
Pattanayak, S. K., S. Wunder, and P. J. Ferraro (2010): "Show Me the Money: Do Payments Supply Environmental Services in Developing Countries?," Review of Environmental Economics and Policy.

Robalino, J., and A. Pfaff (2013): "Ecopayments and Deforestation in Costa Rica: A Nationwide Analysis of PSA's Initial Years," Land Economics, 89(3), 432-448.

Silva-Chávez, G., B. SchaAp, and J. Breitfeller (2015): "REDD+ Finance Flows 2009-2014: Trends and Lessons Learned in REDDX Countries," Report, Forest Trends.

Solon, G., S. J. Haider, and J. M. Wooldridge (2015): "What Are We Weighting For?," Journal of Human Resources, 50(2), 301-316.

Somanathan, E., R. Prabhakar, and B. S. Mehta (2009): "Decentralization for Cost-Effective Conservation," Proceedings of the National Academy of Sciences, 106(11), 4143-4147.

Stern, N. (2006): The Economics of Climate Change: The Stern Review. Cambridge University Press, Cambridge, UK.

Uchida, E., J. Xu, Z. Xu, and S. Rozelle (2007): "Are The Poor Benefiting From China's Land Conservation Program?," Environment and Development Economics, 12(04), 593-620.

United Nations FCCC (2002): "Report of the Conference of the Parties on Its Seventh Session, Held at Marrakesh From 29 October to 10 November 2001," Conference report, United Nations Framework Convention on Climate Change.

United Nations FCCC (2015): "Paris Agreement under the United Nations Framework Convention on Climate Change," 21st Conference of Parties, Paris, France.

Van der Werf, G. R., D. C. Morton, R. S. DeFries, J. G. Olivier, P. S. Kasibhatla, R. B. Jackson, G. J. Collatz, and J. Randerson (2009): " $\mathrm{CO}_{2}$ Emissions From Forest Loss," Nature Geoscience, 2(11), 737-738.

World Resources Institute (2016): "Global Forest Watch," http://www.globalforestwatch.org.

Wunder, S. (2007): "The Efficiency of Payments for Environmental Services in Tropical Conservation," Conservation Biology, 21(1), 48-58.

Wunder, S., S. Engel, and S. Pagiola (2008): "Taking Stock: A Comparative Analysis of Payments for Environmental Services Programs in Developed and Developing Countries," Ecological Economics, 65(4), 834-852. 
Table 1: Descriptive statistics and randomization balance

\begin{tabular}{|c|c|c|c|}
\hline & $\begin{array}{c}\text { Treatment } \\
\text { (1) }\end{array}$ & $\begin{array}{c}\text { Control } \\
(2)\end{array}$ & $\begin{array}{l}\text { Std. diff. } \\
\quad(3)\end{array}$ \\
\hline Household head's age & $\begin{array}{c}47.499 \\
{[13.605]}\end{array}$ & $\begin{array}{c}47.589 \\
{[14.659]}\end{array}$ & 0.003 \\
\hline Household head's years of education & $\begin{array}{l}7.715 \\
{[4.003]}\end{array}$ & $\begin{array}{c}7.931 \\
{[4.187]}\end{array}$ & -0.056 \\
\hline IHS of self-reported land area (ha) & $\begin{array}{c}4.062 \\
{[1.021]}\end{array}$ & $\begin{array}{c}4.004 \\
{[0.968]}\end{array}$ & 0.053 \\
\hline Self-reported forest area (ha) & $\begin{array}{c}1.727 \\
{[3.318]}\end{array}$ & $\begin{array}{c}2.068 \\
{[12.413]}\end{array}$ & -0.042 \\
\hline Cut any trees in the last 3 years & $\begin{array}{c}0.845 \\
{[0.362]}\end{array}$ & $\begin{array}{c}0.858 \\
{[0.350]}\end{array}$ & -0.031 \\
\hline Cut trees to clear land for cultivation & $\begin{array}{c}0.236 \\
{[0.425]}\end{array}$ & $\begin{array}{l}0.241 \\
{[0.428]}\end{array}$ & -0.016 \\
\hline Cut trees for timber products & $\begin{array}{c}0.704 \\
{[0.457]}\end{array}$ & $\begin{array}{c}0.721 \\
{[0.449]}\end{array}$ & -0.037 \\
\hline Cut trees for emergency/lumpy expenses & $\begin{array}{c}0.250 \\
{[0.433]}\end{array}$ & $\begin{array}{c}0.292 \\
{[0.455]}\end{array}$ & -0.088 \\
\hline IHS of total revenue from cut trees & $\begin{array}{c}1.238 \\
{[2.118]}\end{array}$ & $\begin{array}{c}1.397 \\
{[2.248]}\end{array}$ & -0.085 \\
\hline Rented any part of land & $\begin{array}{c}0.163 \\
{[0.370]}\end{array}$ & $\begin{array}{c}0.198 \\
{[0.399]}\end{array}$ & -0.091 \\
\hline Dispute with neighbor about land & $\begin{array}{c}0.218 \\
{[0.413]}\end{array}$ & $\begin{array}{c}0.206 \\
{[0.405]}\end{array}$ & 0.035 \\
\hline Involved in any environmental program & $\begin{array}{c}0.100 \\
{[0.301]}\end{array}$ & $\begin{array}{c}0.111 \\
{[0.315]}\end{array}$ & -0.035 \\
\hline Agree: Deforestation affects the community & $\begin{array}{c}0.539 \\
{[0.499]}\end{array}$ & $\begin{array}{c}0.548 \\
{[0.498]}\end{array}$ & -0.014 \\
\hline Agree: Need to damage envi. to improve life & $\begin{array}{c}0.064 \\
{[0.245]}\end{array}$ & $\begin{array}{c}0.043 \\
{[0.204]}\end{array}$ & 0.089 \\
\hline Tree cover in land circle (ha) & $\begin{array}{c}4.355 \\
{[12.466]}\end{array}$ & $\begin{array}{c}3.845 \\
{[9.178]}\end{array}$ & 0.050 \\
\hline Weighted tree cover in land circle (ha) & $\begin{array}{c}4.403 \\
{[11.643]}\end{array}$ & $\begin{array}{c}3.999 \\
{[8.252]}\end{array}$ & 0.057 \\
\hline$\%$ of land circle with tree cover & $\begin{array}{c}0.199 \\
{[0.161]}\end{array}$ & $\begin{array}{c}0.209 \\
{[0.157]}\end{array}$ & -0.044 \\
\hline$\%$ change in vegetation, $1990-2010$ & $\begin{array}{c}0.035 \\
{[0.066]}\end{array}$ & $\begin{array}{c}0.037 \\
{[0.058]}\end{array}$ & -0.016 \\
\hline $\begin{array}{l}\text { Observations (forest owners) } \\
\text { Number of villages }\end{array}$ & $\begin{array}{c}564 \\
60\end{array}$ & $\begin{array}{c}535 \\
61\end{array}$ & \\
\hline
\end{tabular}

Notes: The table reports subsample means with standard deviations in brackets. The last column reports the regression-adjusted difference in mean between the treatment and control subsample divided by the pooled standard deviation, and an asterisk denotes that this difference has a p-value less than 0.10 . The standardized difference and p-value are based on a regression with subcounty fixed effects, with clustering at the village level. IHS denotes the inverse hyperbolic sine transformation of the variable. Weighted forest cover is the mean weighted by the proportion of the forest owner's land with valid satellite data. 
Table 2: Program take-up

\begin{tabular}{lcccc}
\hline & Take-up & $\begin{array}{c}\text { Amount } \\
\text { paid }\end{array}$ & $\begin{array}{c}\text { Amount } \\
\text { paid for } \\
\text { avoided } \\
\text { deforesta- } \\
\text { tion }\end{array}$ & $\begin{array}{c}\text { Proportion } \\
\text { of eligible } \\
\text { amount } \\
\text { paid }\end{array}$ \\
& $(1)$ & $(2)$ & $(3)$ & $(4)$ \\
\hline Treated & $0.319^{* * *}$ & $8.991^{* * *}$ & $7.962^{* * *}$ & $0.254^{* * *}$ \\
& {$[0.030]$} & {$[1.862]$} & {$[1.799]$} & {$[0.026]$} \\
\hline Control group mean & 0.011 & 0.416 & 0.403 & 0.007 \\
Observations & 1,099 & 1,099 & 1,099 & 1,099 \\
\hline
\end{tabular}

Notes: Standard errors are clustered by village. Asterisks denote significance: ${ }^{*} p<.10,{ }^{* *} p<.05,{ }^{* * *}$ $p<.01$. All columns include subcounty fixed effects and the four village-level baseline variables used to balance the randomization: number of PFOs in baseline sample, average weekly earnings per capita, distance to the nearest main road, and average size of the reported land nearest the dwelling. Amount paid and Amount paid for conservation are in 10,000 UGX. Outcome data are from CSWCT administrative data. 
Table 3: Effect of PES program on forest cover

\begin{tabular}{|c|c|c|c|c|c|}
\hline & \multicolumn{3}{|c|}{ PFO-level land circles } & \multicolumn{2}{|c|}{ Village boundaries } \\
\hline & $\begin{array}{c}\text { Tree cover } \\
\text { (ha) } \\
\text { (1) }\end{array}$ & $\begin{array}{c}\text { Tree cover } \\
\text { (ha) } \\
\text { (2) }\end{array}$ & $\begin{array}{c}\text { Change in } \\
\text { tree cover } \\
\text { (3) }\end{array}$ & $\begin{array}{c}\text { Tree cover } \\
\text { (ha) } \\
\text { (4) }\end{array}$ & $\begin{array}{c}\text { Change in } \\
\text { tree cover } \\
\text { (5) }\end{array}$ \\
\hline Treated & $\begin{array}{l}0.246^{* *} \\
{[0.109]}\end{array}$ & $\begin{array}{l}0.273^{* *} \\
{[0.107]}\end{array}$ & $\begin{array}{l}0.273^{* *} \\
{[0.107]}\end{array}$ & $\begin{array}{c}4.315 \\
{[2.660]}\end{array}$ & $\begin{array}{l}4.650^{*} \\
{[2.607]}\end{array}$ \\
\hline Baseline outcome & $\begin{array}{c}0.998^{* * *} \\
{[0.034]}\end{array}$ & $\begin{array}{c}1.005^{* * *} \\
{[0.072]}\end{array}$ & & $\begin{array}{c}0.953^{* * *} \\
{[0.026]}\end{array}$ & \\
\hline Control group mean & 3.650 & 3.650 & -0.349 & 155.530 & -13.371 \\
\hline Control variables & No & Yes & Yes & Yes & Yes \\
\hline Observations & 995 & 995 & 995 & 121 & 121 \\
\hline
\end{tabular}

Notes: Standard errors are clustered by village in columns 1 to 3 and are heteroskedasticity-robust in columns 4 and 5. Asterisks denote significance: ${ }^{*} p<.10,{ }^{* *} p<.05,{ }^{* * *} p<.01$. All regressions and means are weighted by the proportion of available satellite data. Tree cover is measured in hectares (ha). All columns include subcounty fixed effects and the four village-level baseline variables used to balance the randomization. The control variables included in columns 2 to 5 are the 1990 and 2010 area covered by photosynthetic vegetation and dummy variables for the date of the baseline satellite image. The first 3 columns use a land circle centered on the PFO's home that is twice his self-reported land area, and the next 2 columns use village boundaries. 
Table 4: Heterogeneous effects on forest cover

Heterogeneous treatment effects on tree cover by:

\begin{tabular}{|c|c|c|c|c|c|c|c|c|}
\hline & $\begin{array}{l}\text { Above- } \\
\text { median } \\
\text { tree cover } \\
\text { in land } \\
\text { circle } \\
\quad(1)\end{array}$ & $\begin{array}{l}\% \text { of land } \\
\text { circle with } \\
\text { tree cover } \\
(2)\end{array}$ & $\begin{array}{c}\text { Cut any } \\
\text { trees in } \\
\text { the last } 3 \\
\text { years } \\
(3)\end{array}$ & $\begin{array}{l}\text { Cut trees } \\
\text { to clear } \\
\text { land for } \\
\text { cultivation } \\
\text { (4) }\end{array}$ & $\begin{array}{l}\text { Cut trees } \\
\text { for timber } \\
\text { products } \\
\text { (5) }\end{array}$ & $\begin{array}{l}\text { Cut trees } \\
\text { for emer- } \\
\text { gency/lumpy } \\
\text { expenses } \\
\text { (6) }\end{array}$ & $\begin{array}{l}\text { IHS of } \\
\text { total } \\
\text { revenue } \\
\text { from cut } \\
\text { trees } \\
\quad(7)\end{array}$ & $\begin{array}{c}\text { Predicted } \\
\text { change in } \\
\text { tree cover } \\
(8)\end{array}$ \\
\hline Treat $\times$ Characteristic & $\begin{array}{c}0.469^{* *} \\
{[0.200]}\end{array}$ & $\begin{array}{l}1.964^{* *} \\
{[0.927]}\end{array}$ & $\begin{array}{c}0.429^{* *} \\
{[0.171]}\end{array}$ & $\begin{array}{c}0.032 \\
{[0.133]}\end{array}$ & $\begin{array}{l}0.344^{* *} \\
{[0.167]}\end{array}$ & $\begin{array}{l}0.408^{*} \\
{[0.220]}\end{array}$ & $\begin{array}{c}0.122^{* * *} \\
{[0.043]}\end{array}$ & $\begin{array}{c}-0.694^{* *} \\
{[0.295]}\end{array}$ \\
\hline Treated & $\begin{array}{c}0.021 \\
{[0.070]}\end{array}$ & $\begin{array}{l}-0.157 \\
{[0.150]}\end{array}$ & $\begin{array}{l}-0.092 \\
{[0.138]}\end{array}$ & $\begin{array}{c}0.269^{* *} \\
{[0.119]}\end{array}$ & $\begin{array}{c}0.021 \\
{[0.126]}\end{array}$ & $\begin{array}{c}0.147 \\
{[0.091]}\end{array}$ & $\begin{array}{l}-0.015 \\
{[0.081]}\end{array}$ & $\begin{array}{l}-0.006 \\
{[0.086]}\end{array}$ \\
\hline Characteristic & $\begin{array}{c}-0.578^{* * *} \\
{[0.199]}\end{array}$ & $\begin{array}{c}-3.001^{* *} \\
{[1.176]}\end{array}$ & $\begin{array}{c}-0.329^{* *} \\
{[0.131]}\end{array}$ & $\begin{array}{c}0.071 \\
{[0.116]}\end{array}$ & $\begin{array}{c}-0.334^{* *} \\
{[0.139]}\end{array}$ & $\begin{array}{c}-0.411^{* *} \\
{[0.196]}\end{array}$ & $\begin{array}{c}-0.105^{* * *} \\
{[0.038]}\end{array}$ & $\begin{array}{c}0.523 \\
{[0.352]}\end{array}$ \\
\hline Observations & 995 & 995 & 993 & 995 & 995 & 995 & 993 & 994 \\
\hline
\end{tabular}

Notes: Standard errors are clustered by village. Asterisks denote significance: ${ }^{*} p<.10,{ }^{* *} p<.05,{ }^{* * *} p<.01$. The outcome variable in all columns is endline tree cover, which is measured in hectares. All regressions are weighted by the proportion of available satellite data. All columns include subcounty fixed effects, four village-level baseline variables used to balance the randomization, the baseline outcome, 1990 and 2010 photosynthetic vegetation, and dummy variables for the baseline satellite date. In column 8, predicted tree loss is the predicted value from the regression reported in Appendix Table A3, column 3. 
Table 5: Effects on self-reported tree-cutting

\begin{tabular}{|c|c|c|c|c|c|c|c|}
\hline & $\begin{array}{l}\text { Cut any } \\
\text { trees in the } \\
\text { last year } \\
\text { (1) }\end{array}$ & $\begin{array}{l}\text { Cut trees } \\
\text { to clear } \\
\text { land for } \\
\text { cultivation } \\
\quad(2)\end{array}$ & $\begin{array}{l}\text { Cut trees } \\
\text { for timber } \\
\text { products } \\
\text { (3) }\end{array}$ & $\begin{array}{l}\text { Cut trees } \\
\text { for emer- } \\
\text { gency/lumpy } \\
\text { expenses } \\
(4)\end{array}$ & $\begin{array}{c}\text { Total } \\
\text { revenue } \\
\text { from cut } \\
\text { trees } \\
(5)\end{array}$ & $\begin{array}{l}\text { IHS of total } \\
\text { revenue } \\
\text { from cut } \\
\text { trees } \\
(6)\end{array}$ & $\begin{array}{c}\text { Any } \\
\text { revenue } \\
\text { from cut } \\
\text { trees in the } \\
\text { last year } \\
(7)\end{array}$ \\
\hline Treated & $\begin{array}{c}-0.140^{* * *} \\
{[0.034]}\end{array}$ & $\begin{array}{c}-0.034^{*} \\
{[0.018]}\end{array}$ & $\begin{array}{c}-0.090 * * * \\
{[0.030]}\end{array}$ & $\begin{array}{c}-0.027^{* *} \\
{[0.013]}\end{array}$ & $\begin{array}{l}-28.929 \\
{[21.639]}\end{array}$ & $\begin{array}{c}-0.232^{*} \\
{[0.118]}\end{array}$ & $\begin{array}{c}-0.041^{*} \\
{[0.021]}\end{array}$ \\
\hline Baseline outcome & $\begin{array}{c}0.116^{* * *} \\
{[0.039]}\end{array}$ & $\begin{array}{c}0.065^{* * *} \\
{[0.023]}\end{array}$ & $\begin{array}{c}0.134^{* * *} \\
{[0.029]}\end{array}$ & $\begin{array}{l}0.028^{*} \\
{[0.016]}\end{array}$ & $\begin{array}{c}0.023 \\
{[0.040]}\end{array}$ & $\begin{array}{c}0.143^{* * *} \\
{[0.031]}\end{array}$ & $\begin{array}{c}0.069 * * * \\
{[0.024]}\end{array}$ \\
\hline Lee bound (lower) & $\begin{array}{c}-0.162^{* * *} \\
{[0.035]}\end{array}$ & $\begin{array}{c}-0.041^{* *} \\
{[0.018]}\end{array}$ & $\begin{array}{c}-0.107^{* * *} \\
{[0.030]}\end{array}$ & $\begin{array}{c}-0.031^{* *} \\
{[0.013]}\end{array}$ & $\begin{array}{l}-31.575 \\
{[22.719]}\end{array}$ & $\begin{array}{c}-0.312^{* *} \\
{[0.120]}\end{array}$ & $\begin{array}{c}-0.050^{* *} \\
{[0.022]}\end{array}$ \\
\hline Lee bound (upper) & $\begin{array}{c}-0.103^{* * *} \\
{[0.033]}\end{array}$ & $\begin{array}{c}0.012 \\
{[0.016]}\end{array}$ & $\begin{array}{c}-0.048^{*} \\
{[0.028]}\end{array}$ & $\begin{array}{l}0.021^{*} \\
{[0.010]}\end{array}$ & $\begin{array}{c}5.905^{* *} \\
{[2.339]}\end{array}$ & $\begin{array}{c}0.065 \\
{[0.105]}\end{array}$ & $\begin{array}{c}0.003 \\
{[0.020]}\end{array}$ \\
\hline $\begin{array}{l}\text { Control group mean } \\
\text { Control group SD } \\
\text { Observations } \\
\text { Observations (Lee bounds) }\end{array}$ & $\begin{array}{c}0.453 \\
{[0.498]} \\
1,018 \\
994\end{array}$ & $\begin{array}{c}0.085 \\
{[0.279]} \\
1,018 \\
994\end{array}$ & $\begin{array}{c}0.339 \\
{[0.474]} \\
1,018 \\
994\end{array}$ & $\begin{array}{c}0.069 \\
{[0.254]} \\
1,018 \\
994\end{array}$ & $\begin{array}{c}32.900 \\
{[446.503]} \\
1,018 \\
994\end{array}$ & $\begin{array}{c}0.823 \\
{[2.033]} \\
1,018 \\
994\end{array}$ & $\begin{array}{c}0.152 \\
{[0.359]} \\
1,018 \\
994\end{array}$ \\
\hline
\end{tabular}

Notes: Standard errors are clustered by village. Asterisks denote significance: ${ }^{*} p<.10,{ }^{* *} p<.05,{ }^{* * *} p<.01$. All columns include subcounty fixed effects and the four village-level baseline variables used to balance the randomization. Total revenue from cut trees is in 10,000 UGX. IHS denotes inverse hyperbolic sine transformation. For observations where the baseline outcome is missing, we impute the value as the sample mean, and include in the regression a dummy variable for observations with imputed baseline values. Outcomes refer to the previous one year; baseline values refer to the previous three years. 
Table 6: Effects on land use and protection of land

\begin{tabular}{|c|c|c|c|c|c|c|}
\hline & $\begin{array}{l}\text { Allow others } \\
\text { to gather } \\
\text { firewood } \\
\text { from own } \\
\text { forest } \\
\text { (1) }\end{array}$ & $\begin{array}{l}\text { Decreased } \\
\text { access to } \\
\text { others who } \\
\text { take trees } \\
\text { from forest } \\
\text { in last } 2 \\
\text { years } \\
(2)\end{array}$ & $\begin{array}{l}\text { Increased } \\
\text { level of } \\
\text { patrolling } \\
\text { the forest in } \\
\text { last } 2 \text { years } \\
\text { (3) }\end{array}$ & $\begin{array}{c}\text { Has any } \\
\text { fence around } \\
\text { land with } \\
\text { natural } \\
\text { forest } \\
\text { (4) }\end{array}$ & $\begin{array}{c}\text { Claim to } \\
\text { ownership of } \\
\text { forest } \\
\text { became } \\
\text { stronger in } \\
\text { last } 2 \text { years } \\
\text { (5) }\end{array}$ & $\begin{array}{c}\text { Had dispute } \\
\text { with } \\
\text { neighbors } \\
\text { regarding } \\
\text { land in last } \\
2 \text { years } \\
(6)\end{array}$ \\
\hline Treated & $\begin{array}{c}-0.170 * * * \\
{[0.033]}\end{array}$ & $\begin{array}{c}0.039 \\
{[0.024]}\end{array}$ & $\begin{array}{c}0.109 * * * \\
{[0.039]}\end{array}$ & $\begin{array}{c}0.036 \\
{[0.033]}\end{array}$ & $\begin{array}{c}0.071^{* *} \\
{[0.033]}\end{array}$ & $\begin{array}{l}-0.014 \\
{[0.025]}\end{array}$ \\
\hline Baseline outcome & & & & $\begin{array}{c}0.013 \\
{[0.089]}\end{array}$ & & $\begin{array}{c}0.102^{* * *} \\
{[0.031]}\end{array}$ \\
\hline Lee bound (lower) & $\begin{array}{c}-0.185^{* * *} \\
{[0.033]}\end{array}$ & $\begin{array}{c}0.033 \\
{[0.025]}\end{array}$ & $\begin{array}{c}0.094^{* *} \\
{[0.040]}\end{array}$ & $\begin{array}{c}0.006 \\
{[0.033]}\end{array}$ & $\begin{array}{c}0.049 \\
{[0.032]}\end{array}$ & $\begin{array}{l}-0.024 \\
{[0.026]}\end{array}$ \\
\hline Lee bound (upper) & $\begin{array}{c}-0.146^{* * *} \\
{[0.032]}\end{array}$ & $\begin{array}{c}0.063^{* *} \\
{[0.025]}\end{array}$ & $\begin{array}{c}0.132^{* * *} \\
{[0.040]}\end{array}$ & $\begin{array}{c}0.054 \\
{[0.033]}\end{array}$ & $\begin{array}{c}0.082^{* *} \\
{[0.033]}\end{array}$ & $\begin{array}{c}0.027 \\
{[0.023]}\end{array}$ \\
\hline $\begin{array}{l}\text { Control group mean } \\
\text { Control group SD } \\
\text { Observations } \\
\text { Observations (Lee bounds) }\end{array}$ & $\begin{array}{c}0.427 \\
{[0.495]} \\
976 \\
957\end{array}$ & $\begin{array}{c}0.202 \\
{[0.402]} \\
980 \\
965\end{array}$ & $\begin{array}{c}0.378 \\
{[0.485]} \\
984 \\
965\end{array}$ & $\begin{array}{c}0.667 \\
{[0.472]} \\
1,020 \\
998\end{array}$ & $\begin{array}{c}0.663 \\
{[0.473]} \\
999 \\
982\end{array}$ & $\begin{array}{c}0.140 \\
{[0.347]} \\
1,020 \\
998\end{array}$ \\
\hline
\end{tabular}

Notes: Standard errors are clustered by village. Asterisks denote significance: ${ }^{*} p<.10,{ }^{* *} p<.05,{ }^{* * *} p<.01$. All columns include subcounty fixed effects and the four village-level baseline variables used to balance the randomization. For observations where the baseline outcome is missing, we impute the value as the sample mean, and include in the regression a dummy variable for observations with imputed baseline values. For columns with no baseline coefficient reported, the variable was not collected in the baseline survey. 
Table 7: Socioeconomic effects

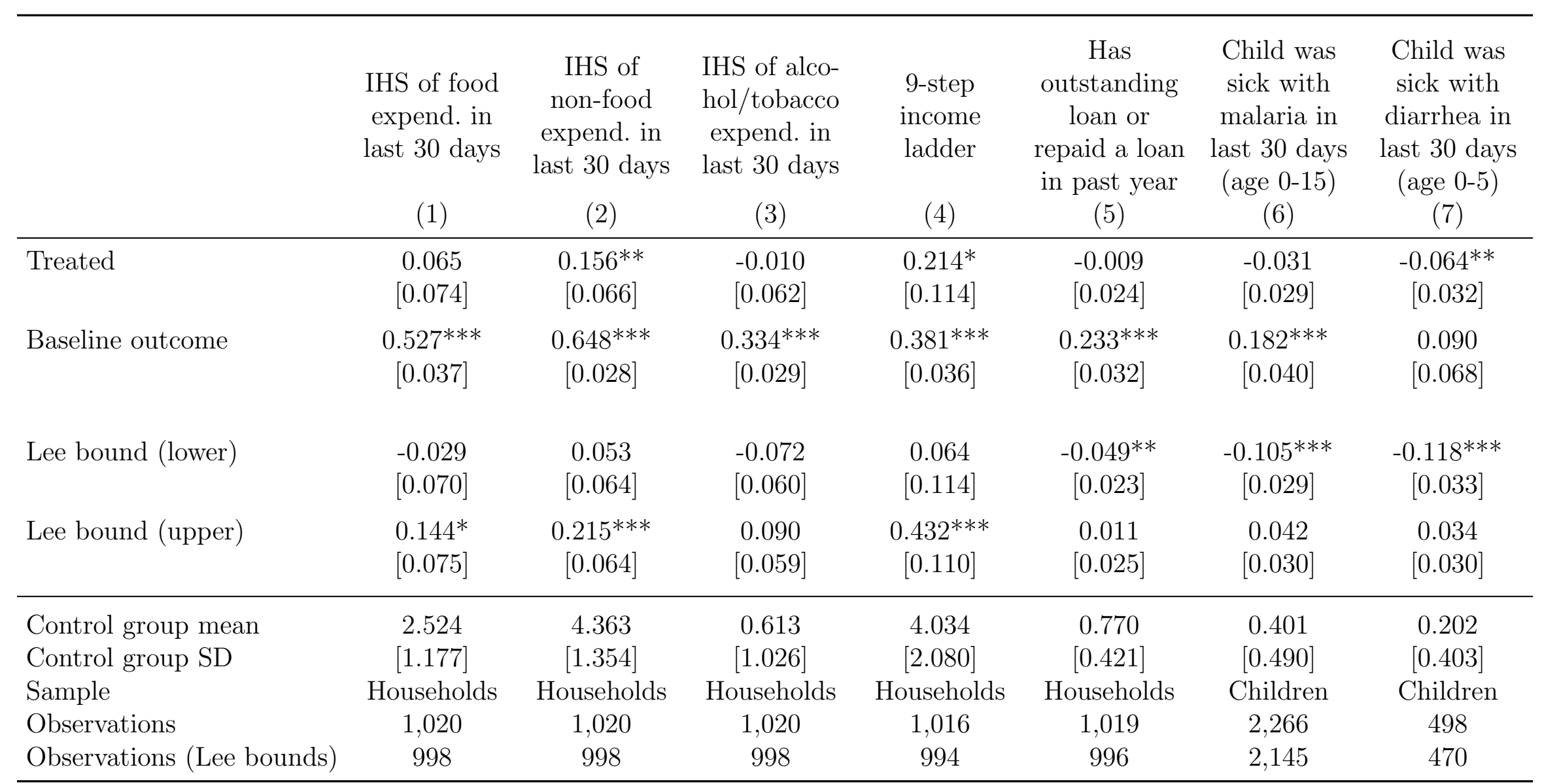

Notes: Standard errors are clustered by village. Asterisks denote significance: $* p<.10, * * p<.05, * * * p<.01$. All columns include subcounty fixed effects and the four village-level baseline variables used to balance the randomization. IHS denotes inverse hyperbolic sine transformation. For observations where the baseline outcome is missing, we impute the value as the sample mean, and include in the regression a dummy variable for observations with imputed baseline values. The outcome in column 4 is the respondent's rating of his income relative to others in his community on a 9-step ladder. In column 6 and 7, each observation is a child and child age-in-years fixed effects are included. Column 6 controls separately for the baseline prevalence among children 0 to 7 and 8 to 15 years old. 
Table 8: Cost-benefit analysis

\begin{tabular}{|l|c|c|c|}
\hline Scenario & $\begin{array}{l}\text { Benefit } \\
\text { per ton of } \\
\text { CO2 }\end{array}$ & $\begin{array}{l}\text { Cost per } \\
\text { ton of } \\
\text { CO2 }\end{array}$ & $\begin{array}{l}\text { Cost- } \\
\text { benefit } \\
\text { ratio }\end{array}$ \\
\hline 1. Base case: Program effects undone over 4 years & $\$ 1.11$ & $\$ 0.57$ & 0.51 \\
\hline 2. Program effects accumulate for final 6 months & $\$ 1.11$ & $\$ 0.43$ & 0.38 \\
\hline 3. Program effects undone immediately & $\$ 0.37$ & $\$ 0.57$ & 1.52 \\
\hline 4. Deforestation resumes at normal rate (permanent delay) & $\$ 0.74$ & $\$ 0.06$ & 0.08 \\
\hline 5. Program effects undone over 2 years & $\$ 0.74$ & $\$ 0.57$ & 0.76 \\
\hline 6. Avg time until emissions is halved to 5 years & $\$ 1.17$ & $\$ 0.57$ & 0.48 \\
\hline 7. Avg time until emissions doubled to 20 years & $\$ 1.00$ & $\$ 0.57$ & 0.57 \\
\hline 8. Monitoring rate remains at 1 spot check per day & $\$ 1.11$ & $\$ 0.66$ & 0.59 \\
\hline
\end{tabular}

Notes: This table compares the costs of the PES program, measured per ton of averted $\mathrm{CO}_{2}$ emissions, with the social benefit of the averted emissions. The base case assumes (a) no further treatment effects during the 0.5 years between endline satellite data collection and program end (b) an average 3-year delay in deforestation (treatment effects undone over 4 years) (c) average time from tree-cutting to $\mathrm{CO}_{2}$ emissions of 10 years, and (d) a monitoring rate of 2 spot checks per monitor per day. Row 2 modifies (a) to assume the treatment effects accumulate at the same rate in the final 0.5 year as was observed in the first 1.5 years. Row 3 modifies (b) to assume a 1-year delay in deforestation (treatment effects undone the day the program ends). Row 4 modifies (b) to assume the averted deforestation and all subsequent deforestation are delayed by the 2 -year duration of the program. Row 5 modifies (a) to assume a 2-year delay in only the averted deforestation during the intervention (treatment effects undone over 2 years). Row 6 and 7 modify (c) to shorten and lengthen the gap between tree-cutting and emissions. Row 8 modifies (d) to assume 1 spot check per monitor per day. See section 6 for further discussion. 


\section{ONLINE APPENDIX: NOT FOR PUBLICATION}

\section{Data Appendix}

\section{Household survey}

Endline respondents: In 53 cases, the endline respondent was a different member of the household than the baseline respondent. In 18 of these cases, the baseline respondent had died, in 3 cases he was too ill to participate, and in 22 cases he was temporarily or permanently away from the village. The remaining 10 cases are miscellaneous reasons.

\section{Remote sensing analysis}

Procurement of images: The QuickBird satellite is operated by DigitalGlobe. We contracted with an image reseller, Apollo Mapping, to task our images.

Top-of-atmosphere reflectance: Calculations for top-of-atmosphere reflectance, which accounts for factors such as solar zenith angle and Earth-Sun distance at acquisition time, were done following DigitalGlobe's "Radiance Conversion of QuickBird Data" technical documentation.

\section{Variable construction}

IHS transformation: The inverse hyperbolic sine transformation is the function $f(x)=\ln \left(x+\sqrt{x^{2}+1}\right)$. Except for values of $x$ close to 0 , it approximates $\ln (x)+\ln (2)$. Before transforming the QuickBird variables with the IHS function, we rescale the variables in levels such that the 10th percentile of the baseline value using actual-sized circles is 1 . We apply the same procedure to the Landsat variables, forest area, and baseline per capita income. For baseline per capita income, the raw 10th percentile is 2500 UGX, and we use the same scale factor for all other monetary values before applying the IHS transformation. The results are insensitive to the scale factors used.

Food, non-food, and alcohol/tobacco expenditures: The categories for food were as follows: tea; soda; milk; sugar; meat; fish; rice; beans; salt; snacks and meals consumed outside home; other foods. the categories for non-food were as follows: petrol and diesel; paraffin; body soap; clothing soap; other cosmetics, combs, razors; transport (excluding petrol and diesel); air time and use of public phones; domestic assistant or farm help; funeral expenses; shoes and sandals; clothing and bedding (not including school uniforms); livestock care (medicine, food, enclosures); school fees (not including uniforms and supplies); school supplies; bride price expenses; religious tithes.

Distance to forest reserves: Distance to forest reserves is the shortest distance between the PFO's home and the boundaries of government forest reserves.

Number of treatment villages within 5 kilometers: For calculating the number of villages near village A, any other village is considered within $5 \mathrm{~km}$ if any portion of its polygon is within $5 \mathrm{~km}$ distance of village A's centroid.

\section{Cost-benefit calculation}

Tons of carbon per hectare: Global Forest Watch uses Landsat data to estimate the biomass in forests globally at a resolution of 30 meters. The most recent data at this resolution are from 2000. We calculate the average carbon per hectare in forests with at least $67 \%$ forest cover within our study village boundaries. The value is 307 tons of above-ground biomass per hectare, and we apply the standard factor of 0.5 to obtain tons of carbon per hectare. 
Appendix Figure A1: Reasons for not taking up the program

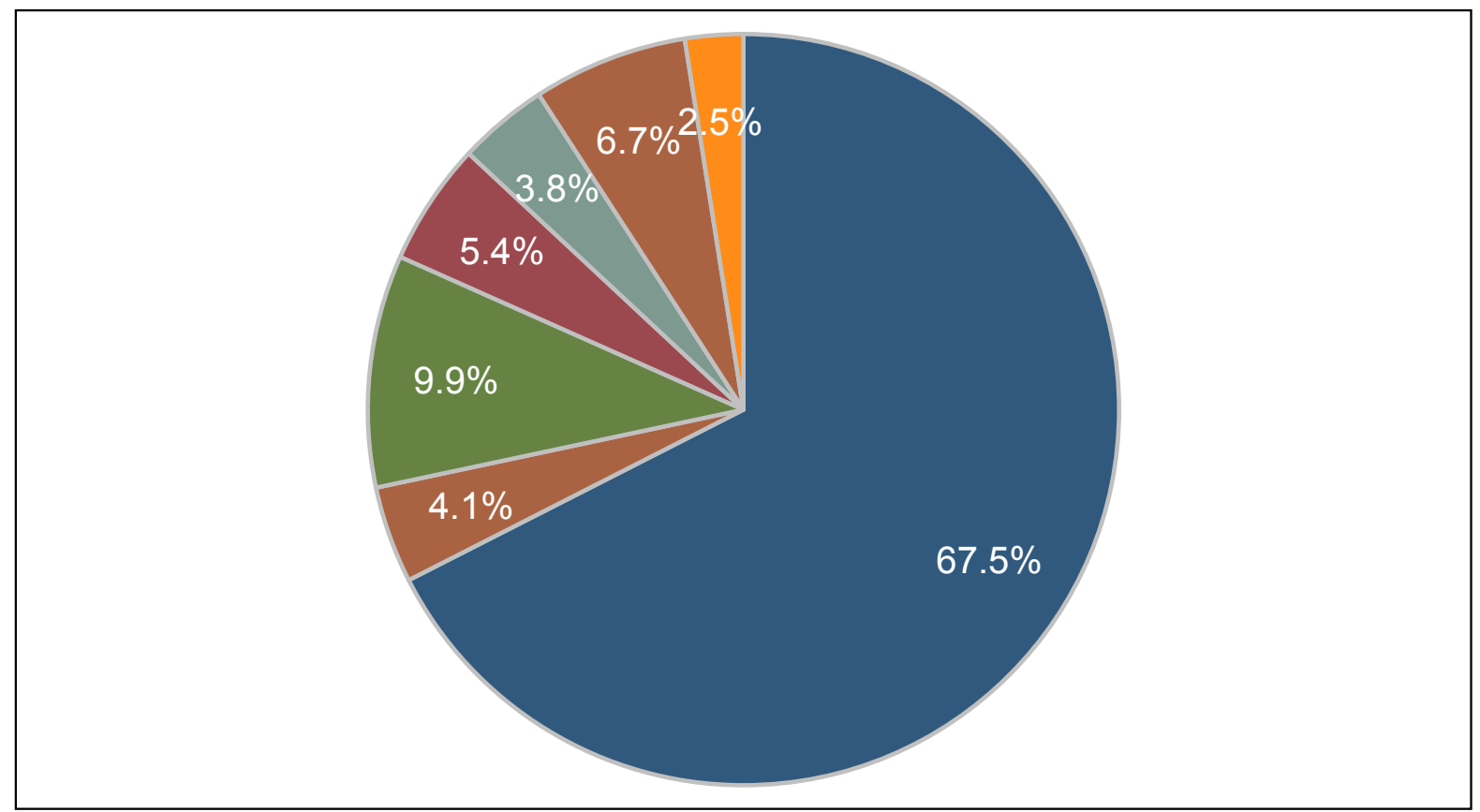

\begin{tabular}{|l|l|l|}
\hline Unaware of program or what it is & Fear land grabs/distrust NGOs \\
Didn't know how to sign up & Want to cut trees/low payment \\
Deemed ineligible by CSWCT & Contract too complicated \\
Other & \\
\hline \begin{tabular}{l}
\hline \\
\hline
\end{tabular} & \\
\hline
\end{tabular}

Notes: This figure is based on responses to questions asked on the endline survey to non-enrollee PFOs in treatment villages. PFOs were asked if they were aware of the program. Those who were aware but said they did not enroll were asked their reason for not enrolling. 
Appendix Figure A2: Proportion of PFO's land with valid remote sensing data

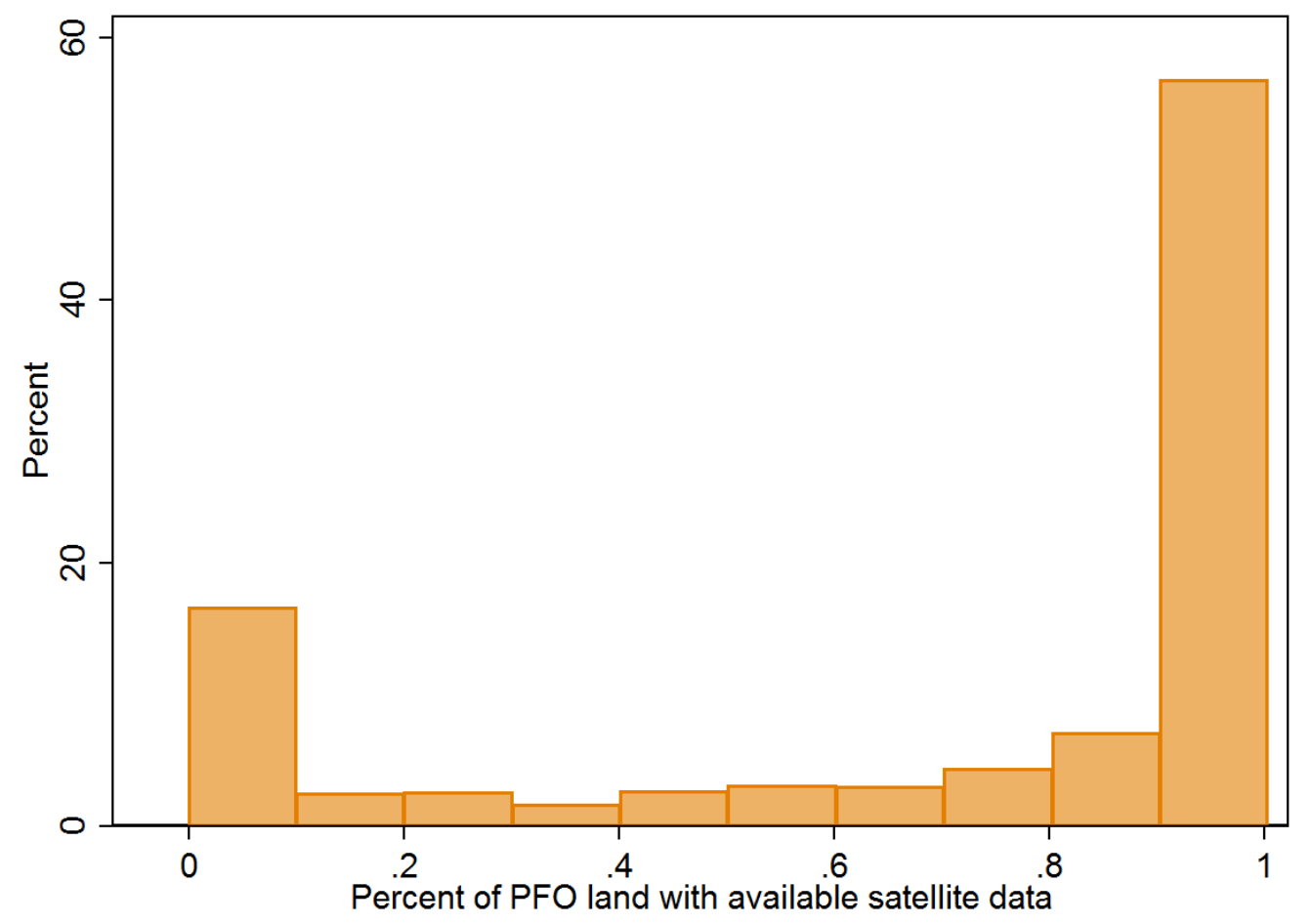

Notes: The figure shows a histogram of the proportion of sample PFOs' land that has available satellite data. PFO land is proxied by a circle twice as large as his self-reported land area. The main source of missing data is cloud cover. Area outside the study villages is also missing remote sensing data. 
Appendix Table A1: Sample attrition

\begin{tabular}{lccc}
\hline & \multicolumn{3}{c}{ Number of PFOs } \\
\cline { 2 - 4 } & $\begin{array}{c}\text { Treatment } \\
\text { group }\end{array}$ & $\begin{array}{c}\text { Control } \\
\text { group }\end{array}$ & Total \\
\hline Baseline survey (with GPS location of PFO home) & 564 & 535 & 1,099 \\
Baseline survey and satellite land circle & 508 & 487 & 995 \\
HH reports owning no land & 2 & 3 & 5 \\
Didn't report land area & 0 & 1 & 1 \\
Entire land circle has cloud cover & 54 & 44 & 98 \\
Baseline survey and endline survey & 512 & 508 & 1,020 \\
Baseline survey, satellite land circle, and endline survey & 463 & 464 & 927 \\
\hline
\end{tabular}

Notes: The top row represents our full sample and the following rows state the number of PFOs with available endline and satellite data (broken down by reason for missing satellite data). 


\section{Appendix Table A2: Determinants of sample attrition}

\begin{tabular}{|c|c|c|c|c|c|c|}
\hline & $\begin{array}{l}\text { All PFOs } \\
\text { (1) }\end{array}$ & $\begin{array}{c}\text { PFOs with } \\
\text { missing } \\
\text { satellite data } \\
(2)\end{array}$ & $\begin{array}{c}\text { PFOs with } \\
\text { missing } \\
\text { endline data } \\
\text { (3) }\end{array}$ & $\begin{array}{l}\text { Std. diff. } \\
(1-2) \\
(4)\end{array}$ & $\begin{array}{c}\text { Adj. std. diff. } \\
(1-2) \\
(5)\end{array}$ & $\begin{array}{c}\text { Std. diff. } \\
(1-3) \\
(6)\end{array}$ \\
\hline Household head's age & $\begin{array}{c}47.543 \\
{[14.122]}\end{array}$ & $\begin{array}{c}47.500 \\
{[13.555]}\end{array}$ & $\begin{array}{c}44.671 \\
{[14.772]}\end{array}$ & 0.035 & -0.070 & $0.207^{*}$ \\
\hline Household head's years of education & $\begin{array}{c}7.820 \\
{[4.093]}\end{array}$ & $\begin{array}{c}8.330 \\
{[4.223]}\end{array}$ & $\begin{array}{c}7.385 \\
{[3.845]}\end{array}$ & -0.147 & $-0.270^{* *}$ & 0.119 \\
\hline IHS of self-reported land area (ha) & $\begin{array}{c}4.034 \\
{[0.996]}\end{array}$ & $\begin{array}{c}3.543 \\
{[1.348]}\end{array}$ & $\begin{array}{l}3.804 \\
{[1.165]}\end{array}$ & $0.540^{* * *}$ & & $0.253^{*}$ \\
\hline Self-reported forest area (ha) & $\begin{array}{c}1.893 \\
{[8.978]}\end{array}$ & $\begin{array}{c}1.213 \\
{[2.500]}\end{array}$ & $\begin{array}{c}1.197 \\
{[1.450]}\end{array}$ & $0.072^{*}$ & -0.088 & $0.078^{* *}$ \\
\hline Cut any trees in the last 3 years & $\begin{array}{c}0.851 \\
{[0.356]}\end{array}$ & $\begin{array}{c}0.760 \\
{[0.429]}\end{array}$ & $\begin{array}{c}0.772 \\
{[0.422]}\end{array}$ & $0.273^{* *}$ & 0.165 & $0.271^{* *}$ \\
\hline Cut trees to clear land for cultivation & $\begin{array}{c}0.238 \\
{[0.426]}\end{array}$ & $\begin{array}{c}0.231 \\
{[0.423]}\end{array}$ & $\begin{array}{c}0.152 \\
{[0.361]}\end{array}$ & 0.022 & 0.018 & $0.199^{*}$ \\
\hline Cut trees for timber products & $\begin{array}{c}0.712 \\
{[0.453]}\end{array}$ & $\begin{array}{c}0.596 \\
{[0.493]}\end{array}$ & $\begin{array}{c}0.696 \\
{[0.463]}\end{array}$ & $0.254^{* *}$ & 0.165 & 0.088 \\
\hline Cut trees for emergency/lumpy expenses & $\begin{array}{c}0.270 \\
{[0.444]}\end{array}$ & $\begin{array}{c}0.212 \\
{[0.410]}\end{array}$ & $\begin{array}{c}0.316 \\
{[0.468]}\end{array}$ & 0.136 & 0.082 & -0.047 \\
\hline IHS of total revenue from cut trees & $\begin{array}{c}1.315 \\
{[2.183]}\end{array}$ & $\begin{array}{c}1.030 \\
{[2.176]}\end{array}$ & $\begin{array}{c}1.086 \\
{[1.992]}\end{array}$ & 0.094 & -0.010 & 0.135 \\
\hline Rented any part of land & $\begin{array}{c}0.180 \\
{[0.384]}\end{array}$ & $\begin{array}{c}0.096 \\
{[0.296]}\end{array}$ & $\begin{array}{c}0.139 \\
{[0.348]}\end{array}$ & $0.257 * * *$ & 0.132 & 0.082 \\
\hline Dispute with neighbor about land & $\begin{array}{c}0.212 \\
{[0.409]}\end{array}$ & $\begin{array}{c}0.173 \\
{[0.380]}\end{array}$ & $\begin{array}{c}0.266 \\
{[0.445]}\end{array}$ & 0.118 & 0.081 & -0.148 \\
\hline Involved in any environmental program & $\begin{array}{c}0.106 \\
{[0.307]}\end{array}$ & $\begin{array}{c}0.071 \\
{[0.259]}\end{array}$ & $\begin{array}{c}0.013 \\
{[0.114]}\end{array}$ & $0.148^{*}$ & 0.103 & $0.335^{* * *}$ \\
\hline Agree: Deforestation affects the community & $\begin{array}{c}0.544 \\
{[0.498]}\end{array}$ & $\begin{array}{c}0.531 \\
{[0.502]}\end{array}$ & $\begin{array}{c}0.434 \\
{[0.499]}\end{array}$ & 0.045 & 0.068 & $0.246^{* *}$ \\
\hline Agree: Need to damage envi. to improve life & $\begin{array}{c}0.054 \\
{[0.226]}\end{array}$ & $\begin{array}{c}0.071 \\
{[0.258]}\end{array}$ & $\begin{array}{c}0.065 \\
{[0.248]}\end{array}$ & -0.071 & -0.077 & -0.088 \\
\hline Treated & $\begin{array}{c}0.513 \\
{[0.500]}\end{array}$ & $\begin{array}{c}0.538 \\
{[0.501]}\end{array}$ & $\begin{array}{c}0.658 \\
{[0.477]}\end{array}$ & -0.072 & -0.098 & $-0.324 * * *$ \\
\hline Take-up & $\begin{array}{c}0.319 \\
{[0.467]}\end{array}$ & $\begin{array}{c}0.250 \\
{[0.437]}\end{array}$ & $\begin{array}{c}0.154 \\
{[0.364]}\end{array}$ & 0.171 & 0.124 & $0.306^{*}$ \\
\hline Tree cover in land circle (ha) & $\begin{array}{c}4.105 \\
{[10.978]}\end{array}$ & & $\begin{array}{c}3.070 \\
{[3.901]}\end{array}$ & & & $0.121^{*}$ \\
\hline$\%$ of land circle with tree cover & $\begin{array}{c}0.204 \\
{[0.159]}\end{array}$ & & $\begin{array}{c}0.211 \\
{[0.150]}\end{array}$ & & & -0.004 \\
\hline$\%$ change in vegetation, $1990-2010$ & $\begin{array}{c}0.036 \\
{[0.062]}\end{array}$ & & $\begin{array}{c}0.027 \\
{[0.060]}\end{array}$ & & & 0.153 \\
\hline Observations & 1,099 & 104 & 79 & & & \\
\hline
\end{tabular}

Notes: The table reports subsample means with standard deviations in brackets. Column 4 reports the regression-adjusted difference in mean between the full sample and the observations with missing satellite data divided by the pooled standard deviation. Asterisks denote significance: ${ }^{*} p<.10,{ }^{* *} p<.05,{ }^{* * *} p<.01$. The standardized difference and p-value are based on a regression with subcounty fixed effects, with clustering at the village level. Column 5 is the regression-adjusted standardized difference when IHS of land area is included as a control variable. IHS denotes the inverse hyperbolic sine transformation of the variable. Column 6 reports the regression-adjusted standardized difference between the full sample and the observations with missing endline data. Summary statistics for Take-up are based on the treatment group only. 
Appendix Table A3: Determinants of program take-up in treatment group

\begin{tabular}{|c|c|c|c|c|}
\hline & $\begin{array}{c}\text { Take-up } \\
\text { (1) }\end{array}$ & $\begin{array}{c}\text { Take-up } \\
\text { (2) }\end{array}$ & $\begin{array}{c}\text { Change in } \\
\text { tree cover } \\
(3)\end{array}$ & $\begin{array}{c}\text { Take-up } \\
(4)\end{array}$ \\
\hline Household head's age & $\begin{array}{c}0.002 \\
{[0.001]}\end{array}$ & & $\begin{array}{c}0.003 \\
{[0.003]}\end{array}$ & \\
\hline Household head's years of education & $\begin{array}{c}0.004 \\
{[0.005]}\end{array}$ & & $\begin{array}{c}0.001 \\
{[0.014]}\end{array}$ & \\
\hline IHS of self-reported land area (ha) & $\begin{array}{l}0.055^{*} \\
{[0.028]}\end{array}$ & $\begin{array}{l}0.059^{* *} \\
{[0.024]}\end{array}$ & $\begin{array}{c}-0.318^{* *} \\
{[0.135]}\end{array}$ & \\
\hline Self-reported forest area (ha) & $\begin{array}{l}-0.004 \\
{[0.006]}\end{array}$ & & $\begin{array}{l}-0.073 \\
{[0.054]}\end{array}$ & \\
\hline Cut any trees in the last 3 years & $\begin{array}{c}0.036 \\
{[0.094]}\end{array}$ & & $\begin{array}{c}0.038 \\
{[0.163]}\end{array}$ & \\
\hline Cut trees to clear land for cultivation & $\begin{array}{c}0.028 \\
{[0.057]}\end{array}$ & & $\begin{array}{c}0.046 \\
{[0.140]}\end{array}$ & \\
\hline Cut trees for timber products & $\begin{array}{c}0.090 \\
{[0.076]}\end{array}$ & & $\begin{array}{c}0.049 \\
{[0.178]}\end{array}$ & \\
\hline Cut trees for emergency/lumpy expenses & $\begin{array}{c}-0.129^{* * *} \\
{[0.041]}\end{array}$ & $\begin{array}{c}-0.099^{* *} \\
{[0.040]}\end{array}$ & $\begin{array}{c}-0.340^{*} \\
{[0.195]}\end{array}$ & \\
\hline IHS of total revenue from cut trees & $\begin{array}{l}-0.010 \\
{[0.010]}\end{array}$ & & $\begin{array}{l}-0.049 \\
{[0.029]}\end{array}$ & \\
\hline Rented any part of land & $\begin{array}{l}-0.046 \\
{[0.067]}\end{array}$ & & $\begin{array}{c}0.004 \\
{[0.175]}\end{array}$ & \\
\hline Dispute with neighbor about land & $\begin{array}{c}0.051 \\
{[0.045]}\end{array}$ & & $\begin{array}{l}-0.063 \\
{[0.109]}\end{array}$ & \\
\hline Involved in any environmental program & $\begin{array}{l}-0.014 \\
{[0.079]}\end{array}$ & & $\begin{array}{l}0.216^{*} \\
{[0.125]}\end{array}$ & \\
\hline Agree: Deforestation affects the community & $\begin{array}{c}0.032 \\
{[0.039]}\end{array}$ & & $\begin{array}{l}-0.037 \\
{[0.086]}\end{array}$ & \\
\hline Agree: Need to damage envi. to improve life & $\begin{array}{c}-0.239^{* * *} \\
{[0.075]}\end{array}$ & $\begin{array}{c}-0.200^{* * *} \\
{[0.068]}\end{array}$ & $\begin{array}{l}-0.403 \\
{[0.346]}\end{array}$ & \\
\hline Tree cover in land circle (ha) & $\begin{array}{c}-0.003^{* *} \\
{[0.001]}\end{array}$ & $\begin{array}{c}-0.003^{* *} \\
{[0.001]}\end{array}$ & & \\
\hline$\%$ change in vegetation, $1990-2010$ & $\begin{array}{c}0.285 \\
{[0.348]}\end{array}$ & & $\begin{array}{l}1.787^{* *} \\
{[0.886]}\end{array}$ & \\
\hline Predicted change in tree cover & & & & $\begin{array}{l}-0.024 \\
{[0.034]}\end{array}$ \\
\hline $\begin{array}{l}\text { Sample } \\
\text { Observations }\end{array}$ & $\begin{array}{l}\text { Treatment } \\
\text { group } \\
564\end{array}$ & $\begin{array}{l}\text { Treatment } \\
\text { group } \\
564\end{array}$ & $\begin{array}{l}\text { Control } \\
\text { group } \\
486\end{array}$ & $\begin{array}{l}\text { Treatment } \\
\text { group } \\
564\end{array}$ \\
\hline
\end{tabular}

Notes: Standard errors are clustered by village. Asterisks denote significance: $* p<.10, * * p<.05, * * * p<.01$. All columns include subcounty fixed effects, and the first three columns include the four village-level baseline variables used to balance the randomization. Missing independent variables have been imputed with the sample mean, and a dummy variable for missing values is included in the regression. IHS denotes the inverse hyperbolic sine function. 
Appendix Table A4: Program impacts on tree-planting

\begin{tabular}{|c|c|c|c|c|c|}
\hline & $\begin{array}{l}\text { Took up } \\
\text { reforestation } \\
\text { option } \\
(1)\end{array}$ & $\begin{array}{c}\text { Reforestation } \\
\text { area } \\
(2)\end{array}$ & $\begin{array}{l}\text { Total trees } \\
\text { planted } \\
\text { (3) }\end{array}$ & $\begin{array}{c}\text { Total trees } \\
\text { survived } \\
\text { (4) }\end{array}$ & $\begin{array}{l}\text { Have } \\
\text { planted trees } \\
\text { in the past } \\
12 \text { mths } \\
\text { (5) }\end{array}$ \\
\hline Treated & $\begin{array}{c}0.149^{* * *} \\
{[0.018]}\end{array}$ & $\begin{array}{c}0.101^{* * *} \\
{[0.016]}\end{array}$ & $\begin{array}{c}31.007^{* * *} \\
{[3.556]}\end{array}$ & $\begin{array}{c}9.813^{* * *} \\
{[1.555]}\end{array}$ & $\begin{array}{c}0.168^{* * *} \\
{[0.040]}\end{array}$ \\
\hline Lee bound (lower) & & & & & $\begin{array}{c}0.156^{* * *} \\
{[0.041]}\end{array}$ \\
\hline Lee bound (upper) & & & & & $\begin{array}{c}0.198^{* * *} \\
{[0.040]}\end{array}$ \\
\hline $\begin{array}{l}\text { Control group mean } \\
\text { Control group SD } \\
\text { Observations } \\
\text { Observations (Lee bounds) }\end{array}$ & $\begin{array}{c}0.002 \\
{[0.043]} \\
1,099\end{array}$ & $\begin{array}{c}0.001 \\
{[0.022]} \\
1,099\end{array}$ & $\begin{array}{c}1.710 \\
{[25.339]} \\
1,099\end{array}$ & $\begin{array}{c}0.933 \\
{[16.534]} \\
1,099\end{array}$ & $\begin{array}{c}0.282 \\
{[0.450]} \\
1,019 \\
998\end{array}$ \\
\hline
\end{tabular}

Notes: Standard errors are clustered by village. Asterisks denote significance: ${ }^{*} p<.10,{ }^{* *} p<.05,{ }^{* * *}$ $p<.01$. All columns include subcounty fixed effects and the four village-level baseline variables used to balance the randomization. The outcome in columns 1 to 4 are from CSWCT administrative data on program participation. Reforestation area is measured in hectares. The outcome in column 5 is from the endline survey. 
Appendix Table A5: Proportional treatment effects on forest cover

\begin{tabular}{lcccccc}
\hline & \multicolumn{3}{c}{ PFO-level land circles } & & \multicolumn{2}{c}{ Village boundaries } \\
\cline { 2 - 3 } & $\begin{array}{c}\text { IHS of tree } \\
\text { cover }\end{array}$ & $\begin{array}{c}\text { IHS of tree } \\
\text { cover }\end{array}$ & $\begin{array}{c}\text { Change in } \\
\text { IHS of tree } \\
\text { cover }\end{array}$ & $\begin{array}{c}\text { IHS of tree } \\
\text { cover }\end{array}$ & $\begin{array}{c}\text { Change in } \\
\text { IHS of tree } \\
\text { cover }\end{array}$ \\
& $(1)$ & $(2)$ & $(3)$ & & $(4)$ & $(5)$ \\
\hline Treated & 0.038 & $0.044^{*}$ & $0.044^{*}$ & & $0.042^{*}$ & $0.043^{*}$ \\
& {$[0.024]$} & {$[0.023]$} & {$[0.023]$} & & {$[0.022]$} & {$[0.022]$} \\
Baseline outcome & $0.982^{* * *}$ & $0.940^{* * *}$ & & & $0.947^{* * *}$ & \\
& {$[0.006]$} & {$[0.015]$} & & & {$[0.033]$} & \\
\hline Control group mean & 2.866 & 2.866 & -0.073 & & 6.936 & -0.095 \\
Control variables & No & Yes & Yes & & Yes & Yes \\
Observations & 995 & 995 & 995 & & 121 & 121 \\
\hline
\end{tabular}

Notes: Standard errors are clustered by village in columns 1 to 3 and are heteroskedasticity-robust in columns 4 and 5. Asterisks denote significance: ${ }^{*} p<.10,{ }^{* *} p<.05,{ }^{* * *} p<.01$. All regressions and means are weighted by the proportion of available satellite data. IHS denotes inverse hyperbolic sine. The outcome is the IHS transformation of tree cover. All columns include subcounty fixed effects and the four village-level baseline variables used to balance the randomization. The control variables included in columns 2 to 5 are the 1990 and 2010 area covered by photosynthetic vegetation and dummy variables for the date of the baseline satellite image. The first 3 columns use a land circle centered on the PFO's home that is twice his self-reported land area, and the next 2 columns use village boundaries. 
Appendix Table A6: Unweighted forest cover results

\begin{tabular}{|c|c|c|c|c|c|}
\hline & \multicolumn{3}{|c|}{ PFO-level land circles } & \multicolumn{2}{|c|}{ Village boundaries } \\
\hline & $\begin{array}{c}\text { Tree cover } \\
\text { (ha) } \\
\text { (1) }\end{array}$ & $\begin{array}{c}\text { Tree cover } \\
\text { (ha) } \\
\text { (2) }\end{array}$ & $\begin{array}{c}\text { Change in } \\
\text { tree cover } \\
\text { (3) }\end{array}$ & $\begin{array}{c}\text { Tree cover } \\
\text { (ha) } \\
\text { (4) }\end{array}$ & $\begin{array}{c}\text { Change in } \\
\text { tree cover } \\
(5)\end{array}$ \\
\hline Treated & $\begin{array}{l}0.183^{*} \\
{[0.099]}\end{array}$ & $\begin{array}{l}0.213^{* *} \\
{[0.095]}\end{array}$ & $\begin{array}{l}0.215^{* *} \\
{[0.098]}\end{array}$ & $\begin{array}{c}4.519 \\
{[2.881]}\end{array}$ & $\begin{array}{l}4.901^{*} \\
{[2.789]}\end{array}$ \\
\hline Baseline outcome & $\begin{array}{c}1.004^{* * *} \\
{[0.034]}\end{array}$ & $\begin{array}{c}1.007^{* * *} \\
{[0.067]}\end{array}$ & & $\begin{array}{c}0.953^{* * *} \\
{[0.025]}\end{array}$ & \\
\hline Control group mean & 3.526 & 3.526 & -0.319 & 146.906 & -12.273 \\
\hline Control variables & No & Yes & Yes & Yes & Yes \\
\hline Observations & 995 & 995 & 995 & 121 & 121 \\
\hline
\end{tabular}

Notes: Standard errors are clustered by village in columns 1 to 3 and are heteroskedasticity-robust in columns 4 and 5. Asterisks denote significance: ${ }^{*} p<.10,{ }^{* *} p<.05,{ }^{* * *} p<.01$. Tree cover is measured in hectares. All columns include subcounty fixed effects and the four village-level baseline variables used to balance the randomization. The control variables included in columns 2 to 5 are the 1990 and 2010 area covered by photosynthetic vegetation and dummy variables for the date of the baseline satellite image. The first 3 columns use a land circle centered on the PFO's home that is twice his self-reported land area, and the next 2 columns use village boundaries. 
Appendix Table A7: Forest cover results removing outliers

\begin{tabular}{|c|c|c|c|c|c|c|}
\hline & \multicolumn{3}{|c|}{$\begin{array}{l}\text { PFO-level land circles } \\
\text { (dropping top 1\%) }\end{array}$} & \multicolumn{3}{|c|}{$\begin{array}{l}\text { PFO-level land circles } \\
\quad \text { (median-sized) }\end{array}$} \\
\hline & $\begin{array}{c}\text { Tree cover } \\
\text { (ha) } \\
\text { (1) }\end{array}$ & $\begin{array}{l}\text { Tree cover } \\
\text { (ha) } \\
\text { (2) }\end{array}$ & $\begin{array}{c}\text { Change in } \\
\text { tree cover } \\
(3)\end{array}$ & $\begin{array}{c}\text { Tree cover } \\
\text { (ha) } \\
\text { (4) }\end{array}$ & $\begin{array}{c}\text { Tree cover } \\
\text { (ha) } \\
(5)\end{array}$ & $\begin{array}{c}\text { Change in } \\
\text { tree cover } \\
\quad(6)\end{array}$ \\
\hline Treated & $\begin{array}{l}0.196^{* *} \\
{[0.088]}\end{array}$ & $\begin{array}{l}0.206^{* *} \\
{[0.081]}\end{array}$ & $\begin{array}{l}0.240^{* *} \\
{[0.097]}\end{array}$ & $\begin{array}{l}0.115^{* *} \\
{[0.052]}\end{array}$ & $\begin{array}{c}0.138^{* * *} \\
{[0.051]}\end{array}$ & $\begin{array}{l}0.147^{* *} \\
{[0.056]}\end{array}$ \\
\hline Baseline outcome & $\begin{array}{c}0.898^{* * *} \\
{[0.026]}\end{array}$ & $\begin{array}{c}0.833^{* * *} \\
{[0.042]}\end{array}$ & & $\begin{array}{c}0.898^{* * *} \\
{[0.027]}\end{array}$ & $\begin{array}{c}0.877^{* * *} \\
{[0.028]}\end{array}$ & \\
\hline Control group mean & 3.239 & 3.239 & -0.336 & 2.112 & 2.112 & -0.209 \\
\hline Control variables & No & Yes & Yes & No & Yes & Yes \\
\hline Observations & 986 & 986 & 986 & 1,002 & 1,002 & 1,002 \\
\hline
\end{tabular}

Notes: Standard errors are clustered by village. Asterisks denote significance: ${ }^{*} p<.10,{ }^{* *} p<.05,{ }^{* * *} p<.01$. All regressions and means are weighted by the proportion of available satellite data. All columns include subcounty fixed effects and the four village-level baseline variables used to balance the randomization. The control variables included in columns 2, 3, 5, and 6 are the 1990 and 2010 area covered by photosynthetic vegetation and dummy variables for the date of the baseline satellite image. The first 3 columns omit the top $1 \%$ of observations based on baseline tree cover. The next 3 columns use land circles that are equal-sized for all PFOs; the size is twice the sample median self-reported land size. 
Appendix Table A8: Forest cover results with different-sized land circles

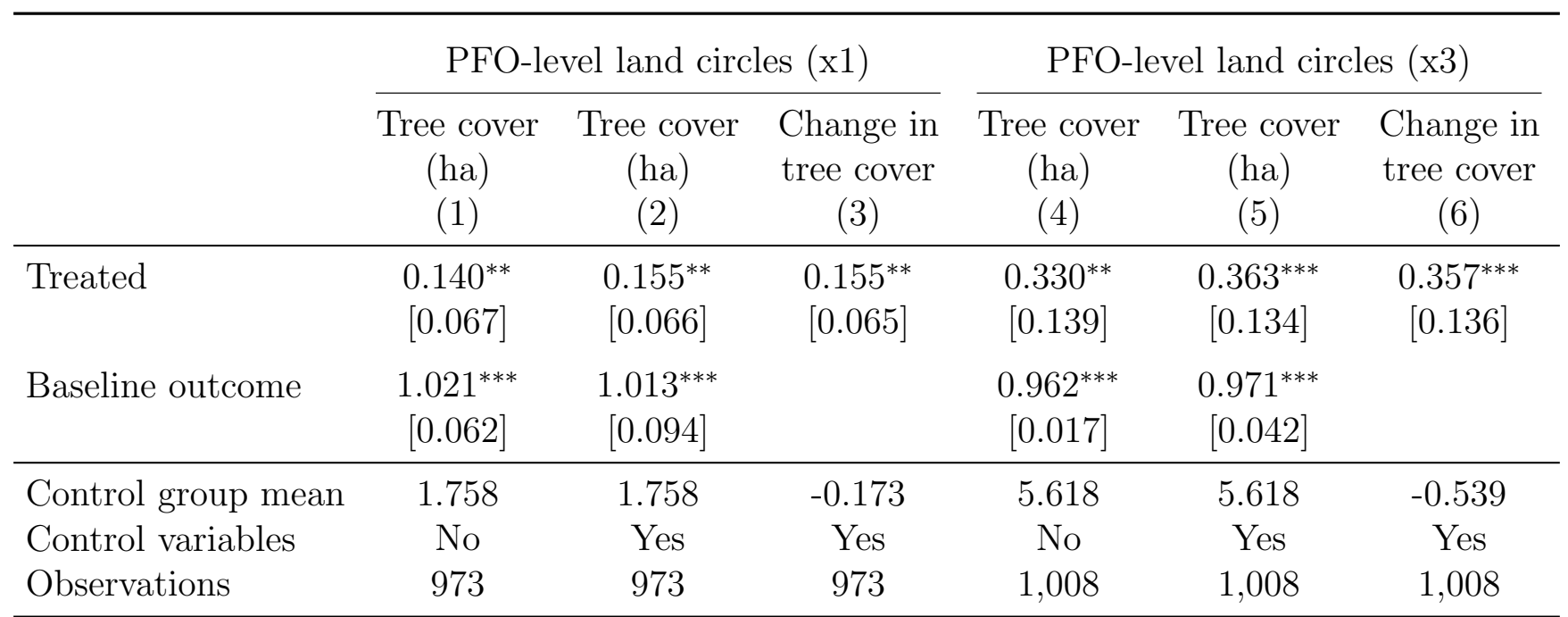

Notes: Standard errors are clustered by village. Asterisks denote significance: ${ }^{*} p<.10,{ }^{* *} p<.05, * * * p<.01$. All regressions and means are weighted by the proportion of available satellite data. All columns include subcounty fixed effects and the four village-level baseline variables used to balance the randomization. The control variables included in columns 2, 3, 5, and 6 are the 1990 and 2010 area covered by photosynthetic vegetation and dummy variables for the date of the baseline satellite image. The first 3 columns use land circles with an area equal to the PFO's self-reported land area. The next 3 columns use a land circle with an area equal to 3 times the PFO's self-reported land area. 
Appendix Table A9: Forest cover results in subsample with baseline satellite data collected prior to randomization

\begin{tabular}{|c|c|c|c|c|c|}
\hline & \multicolumn{3}{|c|}{ PFO-level land circles } & \multicolumn{2}{|c|}{ Village boundaries } \\
\hline & $\begin{array}{c}\text { Tree cover } \\
\text { (ha) } \\
\text { (1) }\end{array}$ & $\begin{array}{c}\text { Tree cover } \\
\text { (ha) } \\
\text { (2) }\end{array}$ & $\begin{array}{c}\text { Change in } \\
\text { tree cover } \\
\text { (3) }\end{array}$ & $\begin{array}{c}\text { Tree cover } \\
\text { (ha) } \\
\text { (4) }\end{array}$ & $\begin{array}{c}\text { Change in } \\
\text { tree cover } \\
\text { (5) }\end{array}$ \\
\hline Treated & $\begin{array}{l}0.300^{* *} \\
{[0.144]}\end{array}$ & $\begin{array}{c}0.407^{* * *} \\
{[0.143]}\end{array}$ & $\begin{array}{l}0.406^{* *} \\
{[0.154]}\end{array}$ & $\begin{array}{l}7.959^{* * *} \\
{[2.838]}\end{array}$ & $\begin{array}{c}8.162^{* * *} \\
{[2.729]}\end{array}$ \\
\hline Baseline outcome & $\begin{array}{c}0.944^{* * *} \\
{[0.032]} \\
\end{array}$ & $\begin{array}{c}0.833^{* * *} \\
{[0.061]} \\
\end{array}$ & & $\begin{array}{c}0.979^{* * *} \\
{[0.024]} \\
\end{array}$ & \\
\hline Control group mean & 4.095 & 4.095 & -0.459 & 172.841 & -16.576 \\
\hline Control variables & No & Yes & Yes & Yes & Yes \\
\hline Observations & 580 & 580 & 580 & 78 & 78 \\
\hline
\end{tabular}

Notes: Standard errors are clustered by village. Asterisks denote significance: ${ }^{*} p<.10,{ }^{* *} p<.05,{ }^{* * *}$ $p<.01$. All regressions and means are weighted by the proportion of available satellite data. All columns include subcounty fixed effects and the four village-level baseline variables used to balance the randomization. The control variables included in columns 2 to 5 are the 1990 and 2010 area covered by photosynthetic vegetation and dummy variables for the date of the baseline satellite image. The sample is restricted to observations for which the baseline satellite image was collected prior to the subcounty lottery. 
Appendix Table A10: Testing for spillover effects and anticipation effects

\begin{tabular}{|c|c|c|c|c|c|c|c|}
\hline & $\begin{array}{c}\text { Tree } \\
\text { cover } \\
(1)\end{array}$ & $\begin{array}{c}\text { Tree } \\
\text { cover } \\
(2)\end{array}$ & $\begin{array}{c}\text { Tree } \\
\text { cover } \\
(3)\end{array}$ & $\begin{array}{c}\text { Get visits } \\
\text { from } \\
\text { timber } \\
\text { dealers } \\
(4)\end{array}$ & $\begin{array}{c}\text { Increase } \\
\text { in timber } \\
\text { dealer } \\
\text { visits last } \\
2 \text { years } \\
(5)\end{array}$ & $\begin{array}{c}\text { Tree } \\
\text { cover } \\
(6)\end{array}$ & $\begin{array}{c}\text { Tree } \\
\text { cover } \\
(7)\end{array}$ \\
\hline Treated & $\begin{array}{c}0.202 \\
{[0.241]}\end{array}$ & $\begin{array}{c}0.313^{* * *} \\
{[0.112]}\end{array}$ & & $\begin{array}{c}0.020 \\
{[0.034]}\end{array}$ & $\begin{array}{l}-0.016 \\
{[0.025]}\end{array}$ & & \\
\hline Treat $\times$ Distance to forest reserve & $\begin{array}{c}0.009 \\
{[0.035]}\end{array}$ & & & & & & \\
\hline Treat $\times$ Contiguous to forest reserve & & $\begin{array}{l}-0.338 \\
{[0.339]}\end{array}$ & & & & & \\
\hline \# of treatment villages within $5 \mathrm{~km}$ & & & $\begin{array}{c}0.019 \\
{[0.039]}\end{array}$ & & & & \\
\hline Believes program likely to come to village & & & & & & $\begin{array}{c}0.076 \\
{[0.075]}\end{array}$ & \\
\hline Believes program ends in 2015 or later & & & & & & & $\begin{array}{l}-0.118 \\
{[0.112]}\end{array}$ \\
\hline Sample & All & All & $\begin{array}{c}\text { Control } \\
\text { group }\end{array}$ & All & All & $\begin{array}{c}\text { Control } \\
\text { group }\end{array}$ & $\begin{array}{l}\text { Treatment } \\
\text { group }\end{array}$ \\
\hline Observations & 995 & 995 & 487 & 1,020 & 1,020 & 487 & 508 \\
\hline
\end{tabular}

Notes: Standard errors are clustered by village. Asterisks denote significance: ${ }^{*} p<.10,{ }^{* *} p<.05,{ }^{* * *} p<.01$. All columns include subcounty fixed effects and the four village-level baseline variables used to balance the randomization. In columns 1 to 3 and 6 and 7 , regressions are weighted by the proportion of available satellite data, and the regressions include 1990 and 2010 Landsat photosynthetic vegetation, the baseline outcome, and dummy variables for the baseline satellite date. The outcomes in columns 4 and 5 are from the endline survey. Column 4 controls for the baseline outcome; the variable in column 5 was not collected at baseline. 